Revue des patrimoines

$20 \mid 2013$

Les patrimoines de la traite négrière et de l'esclavage

\title{
La fabrication du Patrimoine : l'exemple de Gorée (Sénégal)
}

\section{Hamady Bocoum et Bernard Toulier}

\section{(2) OpenEdition}

1 Journals

Édition électronique

URL : https://journals.openedition.org/insitu/10303

DOI : $10.4000 /$ insitu. 10303

ISSN : 1630-7305

Éditeur

Ministère de la Culture

Référence électronique

Hamady Bocoum et Bernard Toulier, «La fabrication du Patrimoine : l'exemple de Gorée (Sénégal) », In Situ [En ligne], 20 | 2013, mis en ligne le 19 juin 2013, consulté le 03 novembre 2021. URL : http:// journals.openedition.org/insitu/10303; DOI : https://doi.org/10.4000/insitu.10303

Ce document a été généré automatiquement le 3 novembre 2021.

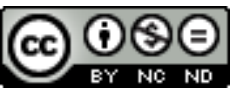

In Situ Revues des patrimoines est mis à disposition selon les termes de la licence Creative Commons Attribution - Pas d'Utilisation Commerciale - Pas de Modification 4.0 International. 


\title{
La fabrication du Patrimoine : l'exemple de Gorée (Sénégal)
}

\author{
Hamady Bocoum et Bernard Toulier
}

${ }_{1}^{1}$ 《 Celui qui vous dit «Gorée est une île » / Celui-là a menti / Cette île n'est pas une île / Elle est continent de l'esprit» (Jean-Louis Roy, 1999) ${ }^{2}$ (fig. nº ${ }^{\circ}$ ). Cet écrivain et diplomate francophone canadien, imprégné du discours des lieux, oppose la matérialité tangible de ce petit bout de terre établi au large de la presqu'île du Cap-Vert, à la portée symbolique de cette île-mémoire, « expression focale de la traite négrière ». 
Figure 1

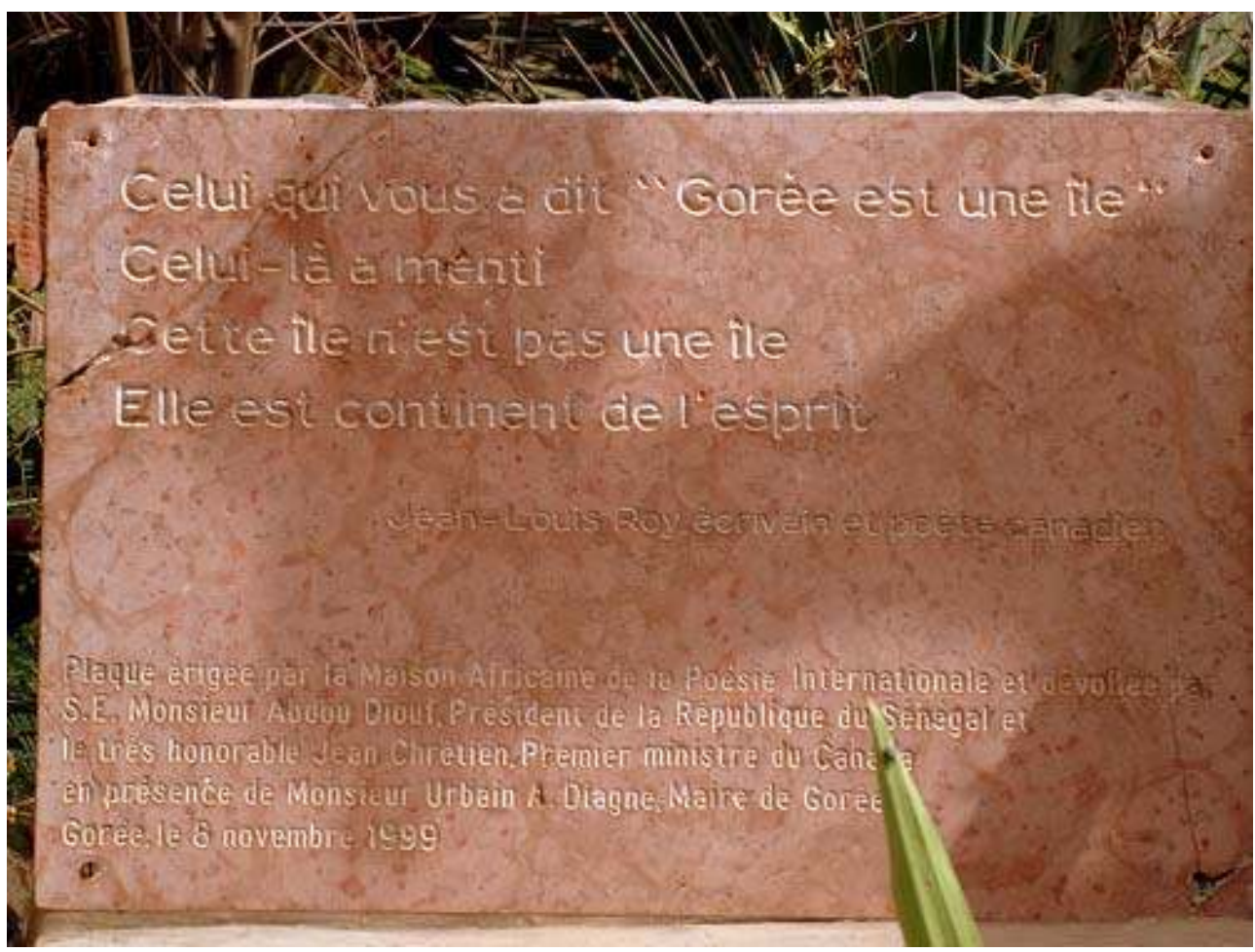

Inscription d'un texte de Jean-Loup Roy. Plaque posée en 1999 dans le jardin jouxtant la Maison des Esclaves à Gorée.

Phot. Jean Krausse, 2011. ( ` Jean Krausse.

Nous ne reviendrons pas ici sur l'état des connaissances concernant l'histoire de l'esclavage et de la traite en Sénégambie et à Gorée. Dès les années 1970-80, les premiers travaux de synthèse sont menés par le professeur MBaye Gueye ${ }^{3}$. En 1997, un article du journal Le Monde mettant en cause la place de Gorée dans la traite atlantique et la fonction de la Maison des Esclaves dans «l'économie symbolique de la mémoire collective » suscite un séminaire sur Gorée et l'esclavage, dirigé par l'Institut Fondamental d'Afrique Noire Cheikh Anta Diop de Dakar ${ }^{4}$. Cette vive riposte "nationale ", relayée par une démarche des historiens africains dans le cadre de la mondialisation en 2001, est supportée depuis 2007 par un programme d'études et de recherches domicilié à l'université de Dakar 5 .

Nous nous attacherons ici à l'observation de la «fabrique » de ce patrimoine mémoriel, depuis la période coloniale jusqu'à nos jours à travers les discours des différents acteurs, chercheurs et historiens, gestionnaires et conservateurs, hommes d'État et responsables de collectivités ou de communautés, responsables d'organisations non gouvernementales ou journalistes, aux différentes échelles locales, nationales ou internationales, à travers les sources archivistiques ou architecturales et les archives vivantes des mémoires-militantes. Ces observations pluridisciplinaires nécessitent un croisement des moyens d'investigation et d'interprétation des sources à travers divers continents.

Comment le site a-t-il été « inventé » et le « centre historique » protégé, comme témoin de l'esclavage et de son abolition dans le cadre d'une mise en tourisme de l'Afrique Occidentale Française (A.O.F.) ? Comment l'État du Sénégal s'est-il approprié cette «greffe coloniale » sur la construction mémorielle et la gestion du cadre bâti qui est 
devenu depuis 1978 un site de portée patrimoniale international, avec son inscription sur la liste du Patrimoine mondial de l'UNESCO ${ }^{6}$ ?

Depuis quelques décennies, Gorée est au centre d'un véritable pèlerinage célébrant la diaspora des afro-descendants qui impose une surenchère compétitive et aux intérêts divergents de construction de musées, d'édification de mémoriaux et de routes touristiques de l'esclavage pour capter les retombées de ce nouveau tourisme dit «culturel $»^{7}$. Quelles en sont les conséquences perceptibles sur le patrimoine et la transmission de la mémoire?

\section{La construction d'un tourisme colonial lié à la mémoire de l'esclavage : 1926-1959}

En 1926, le discours colonial exposé dans le Guide du tourisme en Afrique Occidentale Française présente les Français comme des libérateurs et des civilisateurs «[qui] abolirent l'esclavage et rassemblèrent la terre africaine ${ }^{8} »$. Le touriste est appelé à découvrir, "sous les préjugés négriers et sous les rêveries humanitaires, le caractère paysan des hommes de la savane ${ }^{9} »$.

$\mathrm{Au}$ cours des années 1930, l'agence économique de l'Afrique-Occidentale-Française (A$\mathrm{O}-\mathrm{F}$ ) procède à la mise en valeur touristique des territoires coloniaux et un syndicat d'initiative et de tourisme de l'AOF est installé à Dakar. En 1936, la revue à grand tirage L'Illustration consacre un numéro spécial à "L'œuvre de la France en Afrique occidentale», avec un supplément sur le tourisme. Elle décrit «l'inexprimable et inépuisable attrait» de cette "nature ardente", inquiétante hier, mais accueillante aujourd'hui : «l'AOF est la banlieue tropicale de l'Europe ${ }^{10}$. La même année Air-France inaugure une ligne aérienne vers Dakar ${ }^{11}$.

\section{L'invention de la Maison des Esclaves}

Les espaces voûtés de Gorée établis sous les rez-de-chaussée surélevés des habitations, dans des maisons construites dans le dernier quart du XVIII ${ }^{e}$ siècle ou le premier quart $\mathrm{du}$ XIX ${ }^{\mathrm{e}}$ siècle sont très tôt considérés comme des "captiveries", des "cabanons à esclaves" ou aussi de simples entrepôts. En 1918, le Père Briault nous donne une aquarelle d'un «ancien cabanon à esclaves » établi dans l'actuel presbytère ${ }^{12}$. Selon le Guide du tourisme de 1926, une excursion à l'île de Gorée à partir de Dakar s'impose pour "visiter les anciennes «captiveries » où étaient parqués les esclaves en attendant le retour des négriers, venus à Gorée charger le "bois d'ébène $»^{13}$. Dans un article sur «Gorée la moribonde» paru en 1928, la revue L'Illustration nous présente une reproduction photographique d'une des maisons à cour portant la légende : «au rezde-chaussée logement des esclaves ; au premier étage, salle à manger du traitant $»^{14}$. En 1929, le docteur P. Brau décrit les « cachots antiques, longs et étroits, [des maisons de Gorée qui] puent encore la chair esclave torturée... [Ils ont pu ensuite servir d'entrepôts] à d'autres lots de marchandises moins fragiles, mais non moins âprement discutées : les boucauts de lard salé et les tonnelets d'eaux-de-vie... ${ }^{15}$ ». Dès 1932, dans son guide de visite Gorée, capitale déchue, Robert Gaffiot nous dessine la cour de l'une de ces anciennes "maisons négrières». Il précise dans la légende du dessin l'usage de cette maison où « les esclaves étaient parqués dans le bas-enclos, à l'obscurité, sous les pièces réservées à l'habitation des trafiquants. Le couloir central dessert, à droite et à 
gauche, une douzaine de longues et étroites cellules, dans lesquelles les malheureux étaient entassés et, bien souvent, enchaînés. L'autre extrémité du couloir donne sur la mer : le «négrier » avait ainsi toute facilité pour faire disparaitre les cadavres de ceux qui ne pouvaient subir jusqu'au bout le supplice de cette vie atroce ${ }^{16}{ }_{\|}$(fig. $\left.\mathbf{n}^{0} 2\right)$.

Figure 2

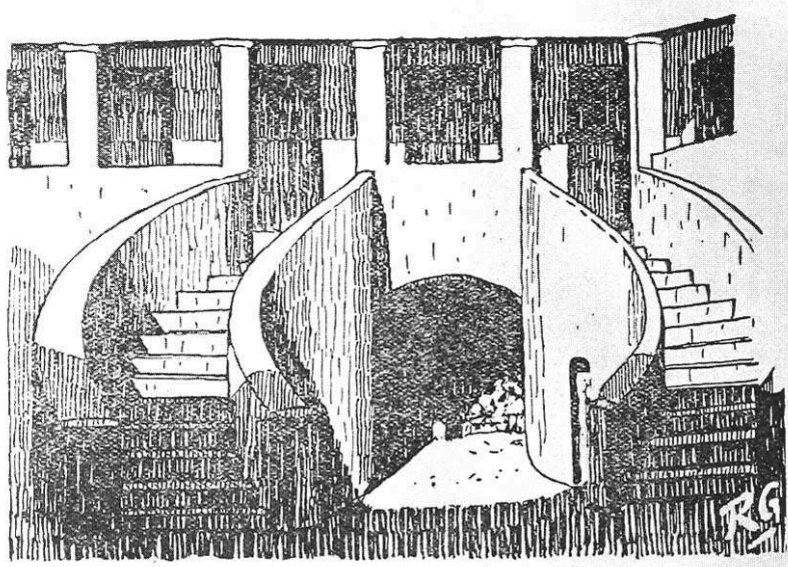

GORÉE - LA COUR D'UNE ANCIENNE MAISON NÉGRIÈRE

Les esclaves étaicnt parqués dans de bas enclos, à l'obscurité, sous les pièces réservées à l'habitation des trafiquants.

Le couloir central dessert, à droite et à gauche, une douzaine de longues et étroites cellules, dans lesquelles les malheureux étaient entassés et bien souvent, enchainés.

L'autre cxtrémité du couloir donne sur la mer : le "négrier" avait ainsi toute faciliti pour faire disparaitre les cadavres de ceux qui ne pouraicht subir jusqu'au bout le supplice de cotte vie atroce.

Gorée. La cour d'une ancienne maison négrière. GAFFIOT, Robert. Gorée, toute petite île. Arcs-etSenans : Éditions de l'Aile, 1933, p. 11. Dessin, signé de la main de l'auteur Robert Gaffiot (R.G.).

Un autre militaire de la marine française, le docteur Pierre-André Cariou, dans son guide non publié Promenade à Gorée, rédigé à partir des années 1940-1943, reprend l'historique et la description de la Maison des Esclaves. Le docteur assombrit encore le tableau dressé dix ans plus tôt par Robert Gaffiot pour l'ancienne maison négrière ${ }^{17}$. En 1951, l'historien et archéologue de l'Institut Français d'Afrique noire (IFAN) Raymond Mauny ${ }^{18}$ dénonce, sans en apporter les preuves, les excès de l'interprétation de Gaffiot ${ }^{19}$ et de Cariou, notamment les considérations sur la fonction de la porte donnant sur la mer, reprenant en partie le témoignage d'un témoin oculaire contemporain, le chevalier de Boufflers, mais qui semblerait plutôt s'appliquer au site de Saint-Louis ${ }^{20}$.

\section{Le discours pédagogique colonial : musées et monuments historiques}

En face de cette Maison dite des esclaves " aux sinistres cellules ", l'IFAN complète et redouble le discours pédagogique à l'intention du touriste par l'installation d'un Musée historique de l'Afrique occidentale française, dans une «belle maison de la fin du XVIII ${ }^{e}$ siècle " édifiée selon Pierre-André Cariou par un [autre] "négrier » dont les cellules du rez-de-chaussée auraient servi, selon le dit docteur de «cachots» aux 
esclaves. Cette maison, dite de Victoria Albis, est achetée grâce à des crédits votés lors de la célébration du centenaire de l'abolition de l'esclavage (1848) puis réhabilitée et inaugurée le 4 juin $1954^{21}$. La présentation, œuvre d'Abdoulaye Ly et de Raymond Mauny, repose sur des bases géographiques et historiques, incluant des cartes ethniques et géographiques de l'AOF. L'une des six salles d'exposition est consacrée à l'esclavage et à son abolition, reprenant ainsi l'orthodoxie de la pensée coloniale ${ }^{22}$.

À l'exemple des sites de la métropole, la promotion touristique est diversifiée, exploitant les ressources de cette "île-mémoire » et de cette " île-musée ». Le circuit de visites mis au point dans les années 1940-1950 est jalonné de deux institutions gérées par l'IFAN : le musée historique et le musée de la Mer (inauguré en 1959, ouvert au public en 1960$)^{23}$ (fig. n⿳3) . Gorée est aussi le laboratoire d'essai pour la protection et la restauration des sites et monuments de l'AOF où seront également impliqués les hommes de science, chercheurs et archéologues de l'IFAN, contribuant ainsi à la promotion d'une politique culturelle coloniale.

Figure 3

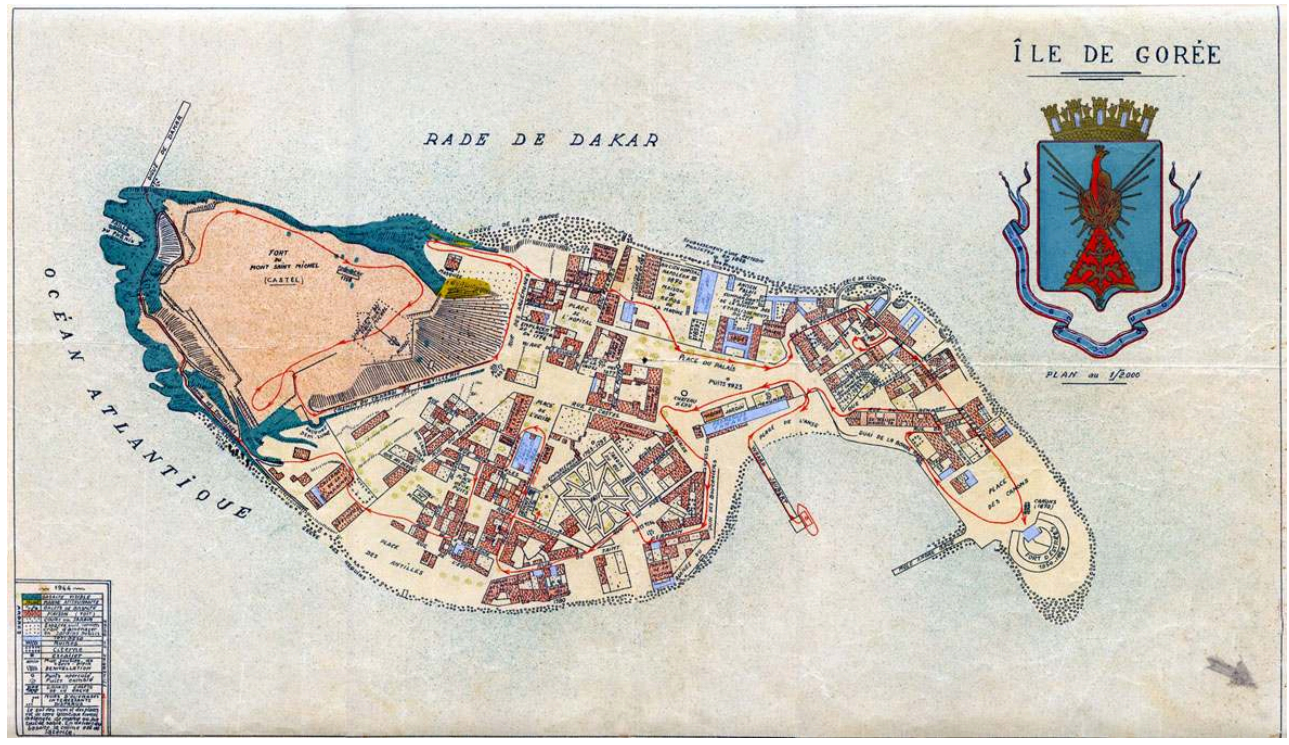

Plan d'un circuit de visite de l'île de Gorée, 1944. CARIOU, Pierre-André. Promenade à Gorée (Sénégal), manuscrit dactylographié, 1951-1952. Plan dépl. en coul. in fine. Aix-en-Provence : Centre des Archives d'Outre-Mer, BIB SOM d4506.

\section{Le classement de l'île au titre des monuments historiques et des sites}

Les dispositions juridiques en vigueur en métropole vont quasi systématiquement être appliquées dans les colonies avec la loi du 31 décembre 1913 relative au classement et à la protection des monuments historiques. Cette initiative sera poursuivie avec notamment le décret du 25 août 1937 portant sur la protection des monuments naturels et des sites de caractère historique, légendaire ou pittoresque des colonies, pays de protectorats et territoires sous mandat relevant du ministère des Colonies ${ }^{24}$. Le pilotage de l'application de cette loi, régulièrement réajustée, est confié à la Commission supérieure des Monuments historiques et des Arts indigènes qui est représentée à Dakar par un délégué permanent assermenté désigné par le Gouverneur général. Le 
dispositif colonial connaîtra une ultime retouche avec la loi $n^{\circ} 56.1106$ du 3 novembre 1956 dont le Sénégal indépendant s'inspirera, très largement, pour préparer la loi 71-12 du 25 janvier 1971 fixant le régime des monuments historiques et des sites archéologiques.

En 1937, quelques jours seulement après la promulgation de l'arrêté de protection par le gouverneur général de l'AOF, André Villard, archiviste-bibliothécaire du Gouvernement général de l'AOF, saisit l'occasion pour proposer le classement de l'île de Gorée, à l'exception de ses terrains militaires, avec restauration des édifices et espaces spécifiques: «Le jardin, la maison dite des Esclaves, l'église, la maison Boufflers, la maison des Donjons, le quartier de la pointe Nord et la rue Bambara et autres points à désigner $[. . .]^{25} \%$. Mais avant même l'adoption de la proposition de classement, les maisons de Gorée sont mises à mal lors de la bataille navale de Dakar entre le 23 et le 25 septembre 1940. Entre 1940 et 1952, une première campagne de restauration et de réhabilitation est mise en place par les autorités militaires de la marine, sans doute soucieuses d'effacer rapidement les traces de l'affrontement avec les alliés, et en déficit de logements. Elle touche près de 90 bâtiments. Les réseaux d'approvisionnement en eau et en électricité sont également modernisés ${ }^{26}$. La proposition d'André Villard est adoptée le 15 novembre 1944, et le classement est étendu à l'île tout entière ${ }^{27}$.

En 1942, Monod plaide en faveur de la sauvegarde de Gorée qui avait particulièrement souffert des bombardements de 1940 et dont de nombreuses maisons étaient déjà en ruine auparavant ${ }^{28}$. «On ne saurait en effet envisager de gaieté de cœur la destruction, ou même une mutilation trop poussée d'un ensemble légué par le passé et dont il est notre devoir de conserver au moins les parties les plus typiques ou les plus curieuses, pour l'instruction ou le déduit de nos successeurs qui nous en voudront, à juste titre, si nous ne leur abandonnons qu'une île de Gorée dépouillée de ce qui fait son cachet et définitivement «banalisée $»^{29} »$. Pour le pouvoir colonial, l'île de Gorée et ses monuments sont d'abord les témoins d'une présence européenne ancienne et forte qui présentent les mêmes critères "scientifiques" de préservation historiques et archéologiques que les monuments métropolitains. L'argumentaire de sauvegarde de l'île reprend les critères habituels en vigueur en Occident pour la protection "monumentale»; on notera l'absence d'argumentation en faveur de la fonction « commerciale » de ce comptoir colonial destiné à la traite.

Dès 1948, à l'occasion du centenaire de l'abolition de l'esclavage, Raymond Mauny propose de consacrer un musée spécifique sur l'esclavage à Gorée et de valoriser, selon lui, «l'un des principaux points où s'effectuait la traite sur la côte occidentale d'Afrique. [...] Nos descendants regretteront le vandalisme de notre époque de fer qui ne sait pas respecter le passé. Mais au fait qu'attend-t-on pour restaurer, protéger, aménager en musée de Gorée, l'une au moins de ces esclaveries ? Ça parle les vieilles pierres... Il serait bon, parfois de les écouter raconter un passé dont on se réjouit qu'il soit révolu. [...] L'AOF est pauvre en sites historiques, ne l'oublions pas : il est d'autant plus nécessaire et urgent de sauvegarder le peu que le passé nous a légué [... et de sauvegarder ces] quelques maisons et pans de murs de basalte qui constituent ses plus anciens titres de noblesse qui disparaissent chaque jour ${ }^{30}$ ».

Ainsi, le pouvoir colonial a jeté les prémices d'une politique de patrimonialisation basée sur le développement touristique d'un circuit de visites, l'ouverture de musées et la mise en valeur de monuments historiques, sans négliger le caractère marin du site. 


\section{Le « conservateur " de la Maison des Esclaves ${ }^{31}$ : un discours sur la mémoire des lieux (1960-2009)}

Après les indépendances, dans la continuité de l'œuvre initiée par le colonisateur, l'État du Sénégal reprend à son compte le discours mémoriel En 1962, le président Léopold Sédar Senghor nomme Boubacar Joseph Ndiaye $^{32}$, ancien sous-officier de l'armée coloniale française, comme " gardien » de la Maison des Esclaves, régularisant ainsi une situation de fait ${ }^{33}$ (fig. $\left.n^{\circ} 4\right)$. La vigueur du discours de ce guide, sans doute inspiré à l'origine par celui du Docteur Cariou, son charisme et la voix imposante de ce « gardien de la mémoire de la traite négrière", l'ont désigné peu à peu comme une sorte de "musée vivant», connu à l'échelle internationale. Gorée doit en grande partie son statut d'île-mémoire de la Traite atlantique à l'éloquence de Joseph Ndiaye, « conservateur » de la Maison des Esclaves.

Figure 4

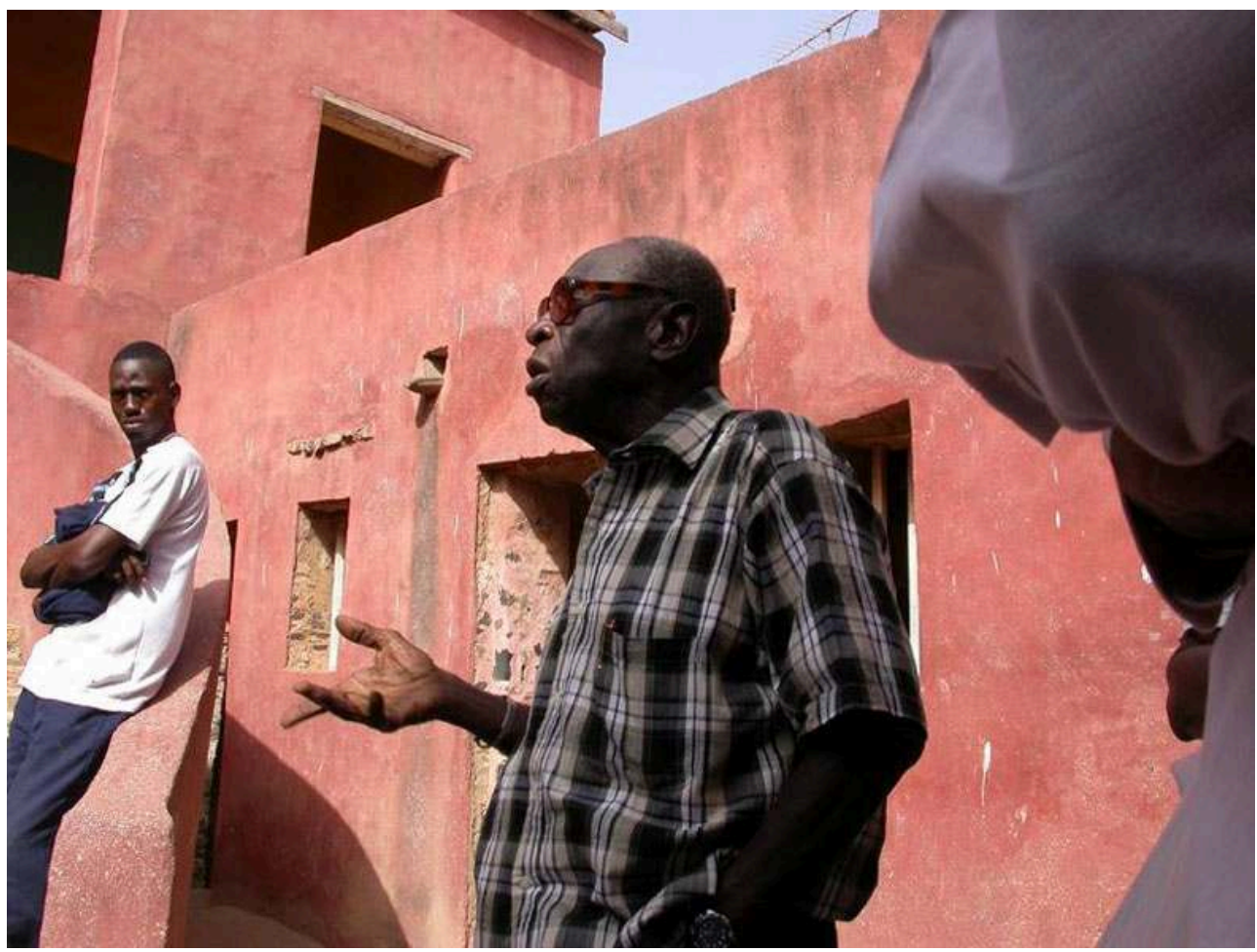

Joseph Ndiaye.

Phot. F. Corbineau, 2005. (c) F. Corbineau.

En 1978, Joseph Ndiaye exprime l'origine de son engagement. "Je suis revenu des guerres européennes et indochinoises profondément marqué par les choses que j'avais vues là-bas. Je suis devenu un nationaliste... Un nationaliste engagé.... ${ }^{34}$. Son récit constitue une re-mémoration de la traite négrière à travers une mise en scène alliant parole, geste et démonstration à l'aide des chaînes en fer reconstituées, avec lesquelles les esclaves étaient attachés. "Ce sanctuaire africain qui est la Maison des Esclaves fut capitale de souffrances et de larmes car des innocents sont morts ici, victimes du temps de la honte. Si ces murs pouvaient parler, ils en diraient long. Heureusement qu'ils se sont tus à jamais ; et moi, je fais parler ces murs ${ }^{35}$ ». Il poursuit son discours sur une 
description fonctionnelle des pièces de la maison. Sous le rez-de-chaussée surélevé, les "cellules" abritent les esclaves. "Il y avait parfois dans cette maison 100 à 150 esclaves répartis dans les différentes cellules de $2 \mathrm{~m} 60$ de carré et qui pouvaient contenir chacune 15 à 20 esclaves qui étaient assis dos contre le mur avec des chaînes les maintenant au cou et au bras. Les enfants étaient séparés de leurs parents, les jeunes filles des femmes... ${ }^{36}$ ».

La fonction de ce discours est significative dans la fabrication d'une mémoire liée à la traite atlantique des esclaves, avec une mise en scène et une représentation imagée de la condition de l'esclave appuyées par des citations, des maximes et des proverbes ${ }^{37}$. La réception $d u$ discours $d u$ "conservateur " se perçoit à travers les diverses réactions observées après la visite du musée et consignées dans le livre d'or ${ }^{38}$. Nombreux sont les guides goréens qui puisent encore une bonne partie de leurs connaissances dans le discours de Joseph Ndiaye. Les réactions observées traduisent des chocs émotionnels qui peuvent déboucher parfois sur des actes spontanés. Le recueillement devant la " porte du voyage sans retour » constitue un acte symbolique qui s'accompagne parfois de rituels, de prières, d'offrandes, de sacrifices, de libations. La signification et la place de l'île dans l'imaginaire de la diaspora noire permettent de mesurer l'impact de cette communauté, en quête d'une identité perdue, dans la cristallisation d'une mémoire de la traite atlantique autour de Gorée.

\section{Les critiques du discours « mémoriel » $\mathrm{T} 1$}

Des contestations naissent sur l'exactitude historique du récit propagé aux visiteurs de la Maison des Esclaves. Dès 1972, le philosophe et chercheur africain Ki-Zerbo, dans son ouvrage "Histoire d'Afrique Noire", s'inquiète de la tournure que peut prendre la défense d'un tel récit qui peut constituer un point de rupture dans la diaspora noire entre l'Afrique et le monde afro des Caraïbes et des Amériques ${ }^{39}$. Deux décennies plus tard, la principale critique émane de deux chercheurs et conservateurs de l'IFAN, Abdoulaye Camara et le père jésuite Joseph Roger de Benoist. Leurs argumentaires sont repris par le journaliste Emmanuel de Roux dans un article paru à Paris dans le journal Le Monde du 27 décembre 1996 sous le titre « Le mythe de la Maison des esclaves qui résiste à la réalité ». L'article remet en cause la fonction de la Maison des Esclaves ainsi que le rôle de l'île de Gorée dans le commerce des esclaves. Le journaliste relate la visite du lieu par son "conservateur" Joseph Ndiaye. "Ce dernier raconte avec émotion l'histoire de cette esclaverie construite par les Hollandais au XVIII siècle, pivot de la traite à Gorée qui vit défiler des centaines de millions d'Africains, enchaînés, vers le Nouveau Monde ${ }^{40} »$. Contrairement aux affirmations de Joseph Ndiaye, Emmanuel de Roux donne la paternité de la maison aux Français, nie l'existence des cellules qui étaient réservées aux esclaves en attente d'embarcation et minimise le nombre d'esclaves ayant transité sur l'île. En conclusion, l'histoire de cette maison présentée par le conservateur ne serait qu'une légende reprise par Joseph Ndiaye, « qui a mis une douzaine d'années à forger un mythe qui, aujourd'hui, a force de $l i^{41}{ }^{4}$ ». La réaction de l'État est vive et rapide. Les 7 et 8 avril 1997, un séminaire réunissant l'ensemble des spécialistes sénégalais et africanistes sur le thème : "Gorée dans la traite atlantique : mythes et réalités » est convoqué dans l'urgence pour riposter à l'imposture ${ }^{42}$.

Dix ans après cette attaque « révisionniste », en 2006, le récit du « conservateur » de la Maison des Esclaves est encore contesté par les descendants de certaines signares qui 
tiennent un autre discours mémoriel et prônent une autre histoire. Dans son ouvrage, Céleste ou le temps des signares, Jean-Luc Angrand nie l'existence d'esclaveries dans les maisons de Gorée : «Il est évident que cette maison comme les autres maisons de Gorée n'ont jamais contenu d'esclaves de traite, les signares étant en général réfractaires à la déportation des esclaves aux Amériques. Les seuls captifs qui existaient dans les maisons de Gorée étaient les captifs de case (domestiques). [...] L'idée pathétique de porte par laquelle seraient passés des esclaves embarquant pour l'Amérique n'était rien qu'une histoire destinée à impressionner les touristes de la fin du XX $\mathrm{XX}^{\mathrm{e}}$ siècle ${ }^{43}$ ». Cette vision de la fonction des supports mémoriels ne prend pas en compte la vraie nature du discours commémoratif car comme l'ont bien montré en 1997 Ibrahima Thioub et Hamady Bocoum «Le discours qui commémore cette fonction de l'île n'a jamais prétendu obéir aux règles universitaires de production du savoir et, en conséquence, ne peut être mesuré à cette aune ${ }^{44} 》$.

En 2009, dans sa récente étude sur la déconstruction du syndrome de Gorée, Ibrahima Seck montre comment l'existence de supports matériels contribue à la cristallisation des mémoires dans certains lieux, témoins de cette période. L'idée d'une "porte du voyage sans retour " n'existe pas seulement à Gorée mais aussi dans les différents points d'embarquement des navires négriers sur la côte occidentale de l'Afrique. " $\mathrm{Au}$ Ghana, Elmina a aussi sa porte du non retour alors qu'il s'agit en réalité d'une meurtrière. À Ouidah, où la traite ne s'est pas accompagnée de l'impressionnante monumentalité visible sur l'ancienne Côte de l'or, le programme de la Route de l'esclave de l'UNESCO a érigé un monument sous la forme d'un énorme portail face à la mer pour donner un support matériel au symbolisme du voyage sans retour ${ }^{45} »$. Il est clair que Gorée a influencé les autres sites qui ont entrepris un travail de remémoration tel qu'il est recommandé par l'UNESCO depuis 1995.

Cette vision romantique de Joseph Ndiaye est transmise par des méta-récits nationalistes ou pan-africanistes dont la réalité est caricaturée d'une manière manichéenne $^{46}$ (fig. $\mathbf{n}^{\circ}$ 5). Ce discours laisse peu de place à une "histoire» plus complexe, " archéologique ", des Africains libres, aux esclaves de case ou aux esclaves domestiques ou aux captifs face aux Africains enchaînés, aux esclaves de traite ou de transit, aux signares et aux métis et à celles des Européens expatriés, des commerçants aux militaires ${ }^{47}$. 
Figure 5

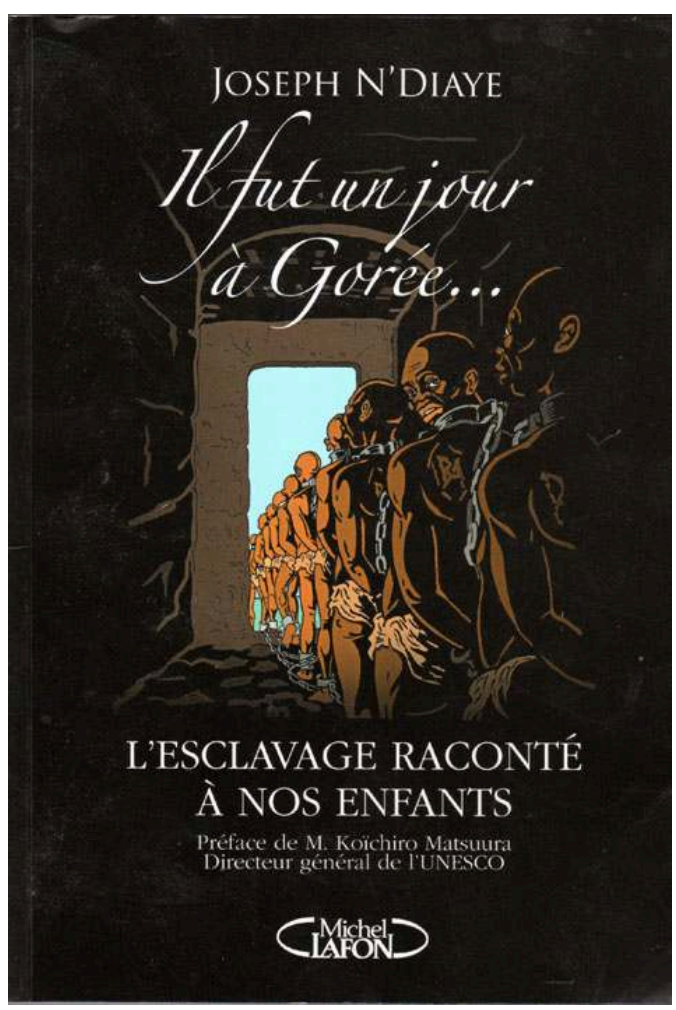

Couverture de l'ouvrage de NDIAYE, Joseph. II fut un jour à Gorée... l'esclavage raconté à nos enfants. Paris : Lafon, 2006, 124 p.

\section{Gorée, entre le discours sur la négritude et le tourisme de mémoire}

L'indépendance une fois acquise, le premier président Léopold Sédar Senghor développe avec le mouvement de la Négritude une orientation culturaliste pour la société sénégalaise, sans rompre avec la francophonie qu'il inscrit dans l'héritage historique du Sénégal et apporte une nouvelle lecture sur la place de Gorée par rapport à la diaspora noire. À partir des années 1980, et pendant deux décennies, le président Abdou Diouf suit la politique de sauvegarde et de mise en valeur de Gorée mise en place par l'UNESCO et veut étendre le message de l'île-mémoire au monde entier par l'érection d'un grand mémorial de l'esclavage. Durant la dernière décennie de la présidence d'Abdoulaye Wade, l'État est moins présent sur le site de Gorée; il est occupé à élever à Dakar d'autres infrastructures dont un monument de la Renaissance africaine et un parc culturel dans lequel sera édifié un musée des Civilisations noires, idée émise en 1971 par le président Senghor ${ }^{48}$.

Le passé de l'île de Gorée et le souvenir des souffrances et des traumatismes subis par l'Afrique et ses diasporas à travers l'esclavage et la traite atlantique, revisité, joue un rôle de premier plan dans l'affirmation de la politique dite "d'enracinement et d'ouverture " chère au président Léopold Sédar Senghor ${ }^{49}$. Le concept de Négritude s'impose comme idéologie du nouvel État indépendant sénégalais qui s'ouvre sur le monde afro-américain. Le président du nouvel État du Sénégal, Léopold Sédar Senghor 
choisit l'île de Gorée comme un des supports physiques de démonstration de son concept sur la Négritude, sans lien direct avec l'esclavage.

En 1966, le président Léopold Sédar Senghor ${ }^{50}$ exprime sa vision culturelle et politique dans l'organisation, à Dakar, du premier Festival mondial des arts nègres projeté lors des congrès des artistes et écrivains noirs de Paris (1956) et de Rome (1959) ${ }^{51}$. «Le premier festival mondial des arts nègres a très précisément pour objet de manifester, avec les richesses de l'art nègre traditionnel, la participation de la Négritude à la Civilisation de l'Universel ${ }^{52}$ " (fig. $\left.\mathbf{n}^{\mathbf{0}} \mathbf{6}\right)$. Gorée est un laboratoire idéal pour le projet post-colonial de la Négritude. Lieu d'échanges culturels, artistiques, littéraires et scientifiques regroupant l'Afrique et sa Diaspora, le Festival est le lieu de rencontres, colloques, expositions, chants, danses, spectacles qui rythment la vie quotidienne des populations de Dakar et de Gorée ${ }^{53}$. Le lancement du Festival a lieu en présence d'André Malraux ${ }^{54}$.

Figure 6

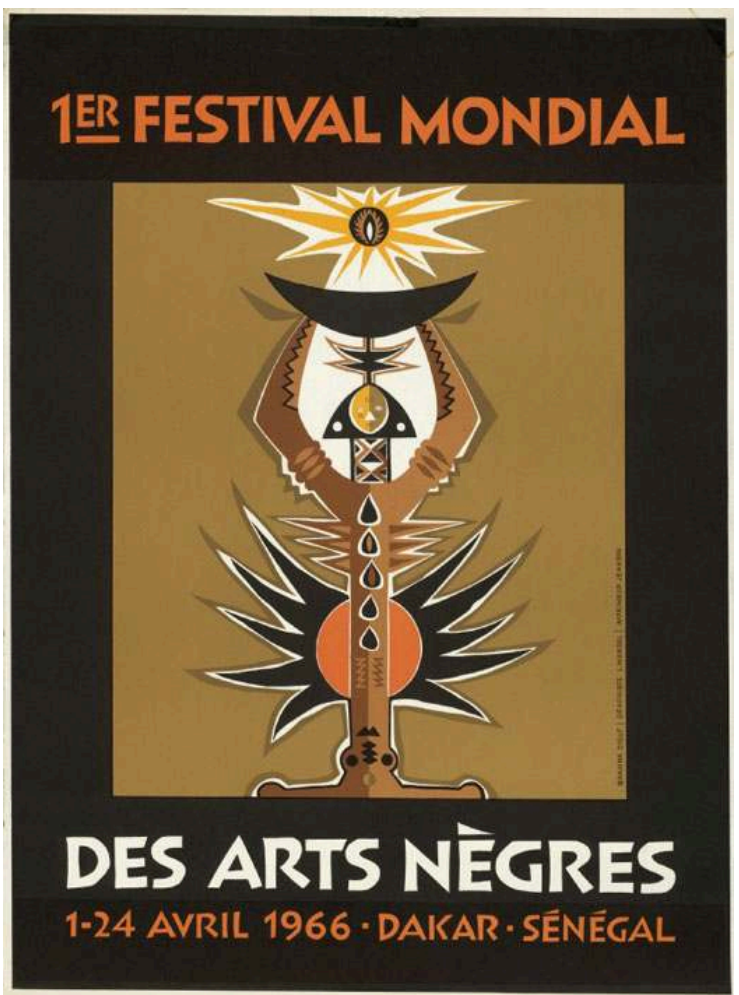

Premier festival mondial des Arts Nègres, 1-24 avril 1966. Dakar, Sénégal. Affiche, 1966. Coll. Express.

Le choix de Gorée pour abriter une des manifestations de ce Festival répond à une volonté du pouvoir politique qui entend faire de l'île un lieu privilégié pour une communion des peuples du monde à travers le dialogue des cultures. Un spectacle « son et lumière ", les «Féeries de Gorée » est monté pour l'occasion : il retrace les grands moments de l'histoire du Sénégal et particulièrement de l'île de Gorée et de son rôle dans l'histoire de l'esclavage ${ }^{55}$. La Maison des Esclaves est restaurée à l'occasion de ce festival.

Les années suivant cette première rencontre mondiale des arts nègres sont marquées par un afflux de touristes afro-américains au Sénégal. À l'heure où le tourisme de mémoire émerge autour des lieux chargés d'histoire et notamment à ceux liés à des 
faits tragiques, le Sénégal concentre ce type de démarche presque exclusivement sur la commémoration de l'esclavage et l'île de Gorée ${ }^{56}$. Des agences américaines proposent aux touristes noirs américains des «Black-History Tours ", leur permettant d'aller se recueillir sur la terre de leurs ancêtres, plus particulièrement à Gorée, et de méditer sur leur tragique destin. «Ainsi, après avoir été, entre l'Afrique et les Amériques noires, le trait d'union symbolique de la désolation, Gorée devient-elle peu à peu un symbole d'espoir, vers où, de plus en plus nombreux, convergent aujourd'hui, en une sorte de pèlerinage, les descendants des déportés de jadis, en quête de leurs racines et tous ceux qui entendent puiser dans son histoire les raisons d'une nouvelle solidarité des peuples ${ }^{57}$ ».

Depuis 2005, la mairie de Gorée organise un festival dans le cadre de la promotion des activités culturelles: le Gorée Diaspora Festival. Cette manifestation internationale constitue un moment de retrouvailles entre la population goréenne et la diaspora ${ }^{58}$. À travers cette manifestation, l'institution municipale vise trois objectifs majeurs: permettre aux membres de la diaspora de retrouver l'identité perdue sur cette îlesouvenir, les faire participer à la sauvegarde de la mémoire et orienter le devenir de Gorée d'un statut de terre d'esclaves vers celle d'un carrefour de dialogue interculturel. En ouvrant ainsi la porte du retour, la commune entend faire rayonner Gorée sur la scène internationale. Cette manifestation constitue un moment de festivités, de recueillement et de souvenir: festivals, rencontres cinématographiques, concerts, expositions, musiques, visite de la Maison des Esclaves, randonnée maritime, etc. Le festival inclut aussi un volet éducatif avec l'organisation de séminaires et d'ateliers de formation, de conférences et de colloques dont les thèmes portent sur l'esclavage, la traite négrière et sa mémoire, le dialogue des peuples et des cultures.

\section{De nouveaux projets d'aménagements touristiques (1968-1970)}

En 1968, l'État sénégalais signe avec le groupe «Euretudes » une convention de mission globale d'aménagement touristique de l'île de Gorée. Dans les termes de cette convention, apparaît une volonté manifeste de sauvegarder le caractère authentique de l'île. «S'agissant d'un lieu dont l'histoire comporte une signification profonde pour les populations du Sénégal, la nature des activités et les aménagements susceptibles d'être implantés dans l'île de Gorée devront tenir compte de ce fait et s'inscrire parfaitement dans son cadre particulier ${ }^{59}$ ». Sous réserve de vérifications, cette étude aurait été confiée à l'architecte Jacques Couelle, qui veut faire de Gorée «l'Acropole du monde noir ${ }^{60}$. «Je veux faire de Gorée un véritable bijou [...] Ce n'est pas pour rien qu'on m'a nommé l'architecte des îles... Il faut un poète pour une île de rêve. Il faut recréer un univers poétique, suspendu [...] recréer une élite de cœur et pas une élite de gens riches, recréer un style et un esprit XVIII ${ }^{\mathrm{e}}$ siècle. Celui qui n'aime pas le passé n'a pas droit au futur. J'accomplis une œuvre de piété. J'agis comme un apôtre, un artiste [...] Le projet ne sera exécuté qu'avec l'accord des 800 Goréens; eux-aussi font partie du décor ». Pour cela, il prévoyait le doublement de la superficie du port, la création d'un plan d'eau sur le Castel, l'importation de milliers d'oiseaux non migrateurs et la reconstitution sur la partie haute de l'île d'un immense village troglodytique. Ce projet n'a heureusement pas été réalisé ${ }^{11}$. 
Cette première mission, à vocation essentiellement touristique, fut rapidement suivie par une autre mission de recensement des principaux sites archéologiques du Sénégal. En partenariat avec l'Unesco et sur la demande des autorités sénégalaises, une mission technique de préservation et de mise en valeur fut organisée sur tout le territoire national. Dans son inventaire sur le patrimoine historique national, Cyr Descamps souligne l'urgence de la protection et de la restauration des sites de Gorée et de SaintLouis qui regorgent de souvenirs légendaires et historiques devenus aujourd'hui des lieux de pèlerinage. D'après ce chercheur, Gorée «est certainement le lieu le plus chargé d'histoire de toute la côte Ouest-africaine. [...]. Toutes les maisons sont de style ancien, une des plus remarquables est la célèbre Maison des esclaves $(. . .)^{62}$ ». L'expert recommande de valoriser ce patrimoine tout en respectant son caractère authentique.

Ces différentes initiatives de mise en valeur culturelle et touristique de l'île, associant ou non son passé de lieu de mémoire de l'esclavage, se concentrent essentiellement sur une politique de rénovation et de sauvegarde du patrimoine immobilier, élaborées par l'État du Sénégal en relation avec de nombreux partenaires et par le maintien de multiples musées aux conceptions encore largement héritées de l'époque coloniale et qui posent problème à la Direction du patrimoine culturel et à l'IFAN Ch. A. Diop.

\section{Le rôle de l'UNESCO et le classement au Patrimoine mondial de l'humanité (1978)}

L'UNESCO insiste sur la protection et la sauvegarde des patrimoines culturels et naturels qui peuvent être une alternative pour appuyer le décollage économique des jeunes États indépendants. Dès 1976, le Sénégal ratifie la Convention de 1972 sur la protection du patrimoine culturel et naturel de l'UNESCO ${ }^{63}$. Parallèlement, le gouvernement sénégalais procède au classement parmi les Monuments historiques de l'île de Gorée, s'inspirant des lois de sauvegarde de l'héritage colonial. Ainsi, en novembre 1975, le site est inscrit sur l'Inventaire des monuments historiques du Sénégal (arrêté $\mathrm{N}^{\circ} 012771$ du 17 novembre 1975), conformément à la loi qui « fixe le régime des monuments historiques et celui des fouilles et découvertes " (loi $\mathrm{n}^{\circ} 71.12 \mathrm{du}$ 25 janvier 1971, décret d'application $n^{\circ} 73.746$ du 8 août 1973).

Réunie à Washington du 5 au 8 septembre 1978, la seconde session du Comité du patrimoine mondial chargé de la mise en œuvre de la Convention pour la sauvegarde du patrimoine culturel et naturel inscrit sur la Liste du patrimoine mondial l'île de Gorée parmi les douze premiers sites. Gorée a été inscrite sur la seule base du critère VI de la convention de $1972^{64}$. L'inscription de lî̂le sur la liste du patrimoine mondial de l'humanité est naturellement une reconnaissance du rôle et de la place de Gorée dans l'économie de la Traite atlantique. Cette inscription a été précédée de multiples missions d'experts, français ou belges, envoyés par l'UNESCO à la demande du gouvernement du Sénégal, afin d'élaborer des études préliminaires pour la sauvegarde du patrimoine architectural.

La mission effectuée en 1974 par A. Grégoire porte sur les monuments historiques de l'île de Gorée et de Saint-Louis du Sénégal. Elle s'inscrit dans la suite de l'expertise de Descamps des années 1969-1970. Grégoire dresse l'inventaire des bâtiments historiques, propose des mesures pour la présentation et la réhabilitation du site, ainsi qu'une évaluation globale des coûts ${ }^{65}$. L'année suivante, une seconde mission réalisée dans le cadre de l'aide aux États-membres pour la préservation et la mise en valeur du 
patrimoine culturel et naturel est conduite par Jean-Pierre Frapolli et Maurice Clerc et précise l'expertise précédente. Elle dresse un plan directeur de rénovation, avec ses aspects juridiques et financiers, en vue des projets de développement touristique que la Banque Internationale pour la Reconstruction et le Développement (BIRD) envisage de financer au Sénégal ${ }^{66}$. En 1977, une troisième mission menée par Michel Parent nuance notamment les conclusions de l'expertise précédente avec des mises en garde sur le développement excessif des équipements touristiques suscitées par l'arrivée de la BIRD $^{67}$. L'année suivante, une quatrième mission menée par Pierre-André Lablaude inclut la réhabilitation du site historique de Gorée dans un large projet touristique de l'ensemble de la Petite Côte ${ }^{68}$.

En novembre 1978, lors de la $20^{e}$ session de la Conférence générale de l'UNESCO, le directeur général est autorisé à entreprendre, en collaboration avec le gouvernement sénégalais, les études techniques nécessaires pour mettre au point un plan d'action détaillé concernant la protection, la préservation, la restauration et la mise en valeur du patrimoine architectural de l'île et pour définir les modalités de sa promotion sous la forme d'une campagne internationale. Il prévoit la sauvegarde de tous les aspects du patrimoine architectural présentant un intérêt historique ou artistique, ainsi qu'une animation culturelle ayant pour objet de les mettre en valeur. À partir de 1979, un comité de sauvegarde veille officiellement au respect de la convention (conformité des ouvrages de réhabilitation, sécurité du bien, etc.).

Toutes ces études et démarches préalables conduisent à l'élaboration d'un Plan d'Action pour la Sauvegarde du patrimoine architectural de Gorée, présenté par l'UNESCO et approuvé en Conseil des Ministres du gouvernement sénégalais le 4 décembre $1980^{69}$. Ce plan prévoit notamment la création [non réalisée] d'un «musée sur la Traite et un centre d'archivage et d'étude sur les Noirs dans le monde " à la maison Cinquèz (à l'angle de la rue de la Pointe et de la rue Dakar, vers le fort d'Estrée), ainsi que le développement de l'Université des Mutants. La restauration de neuf bâtiments historiques est prévue, affectés à des activités socio-culturelles, tel que l'école du Soudan projetée en auberge de jeunesse. Estimé à un coût total de 4 millions de dollars, ce plan de sauvegarde entrevoit, en plus de la restauration des bâtiments, le recrutement temporaire de deux experts associés (architecte-restaurateur) et un consultant dans la muséographie ${ }^{70}$. Le montant de la contribution internationale s'élevait à 315000 dollars. Le Sénégal aurait quant à lui financé pour l'équivalent de plus de 2,3 millions de dollars dont un certain nombre de travaux d'infrastructures et de rénovation non prévus au plan de rénovation de l'UNESCO.

En marge des restaurations et des aménagements, le Sénégal s'engage à concevoir une campagne de sensibilisation de l'opinion publique pour la préservation de l'île. En contrepartie, l'UNESCO publie une brochure ${ }^{71}$, une affiche ${ }^{72}$ (fig. $\mathbf{n}^{\circ} \mathbf{7}$ ), un dossier de presse, l'émission de timbres... et réalise une exposition photographique à Gorée et au siège de l'UNESCO. 


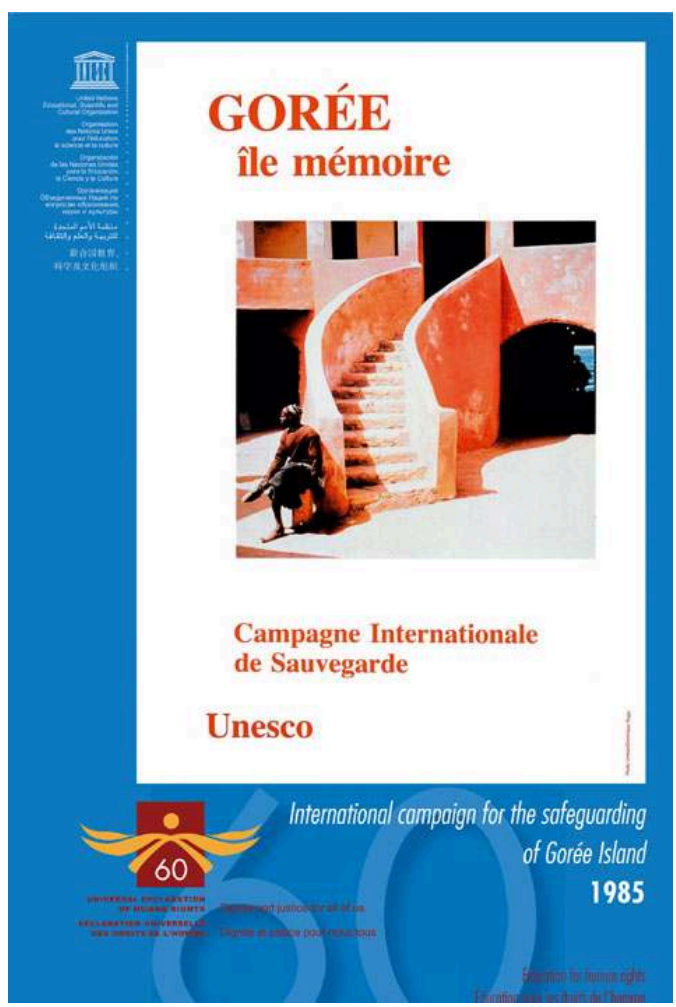

Gorée. Île mémoire. Campagne internationale de sauvegarde. UNESCO. Affiche, 1985, rééd. 2008. Coll. UNESCO.

\section{Le lancement du Plan de sauvegarde de Gorée, l'île- mémoire (1980)}

Le 22 décembre 1980, à la veille de la démission du président Léopold Sédar Senghor, le directeur général de l'UNESCO et sénégalais Amadou Mahtar M'Bow lance un appel en faveur de la sauvegarde de Gorée pour accompagner l'exécution du Plan de sauvegarde de l'île de Gorée approuvé à Dakar quelques jours plus tôt. "Le patrimoine architectural de Gorée doit être sauvé autant pour préserver la haute valeur culturelle de l'île que pour assurer à tous ses habitants des conditions de vie et des activités à la mesure de leurs espoirs". En effet, "à travers les diverses périodes qu'elle a traversées, Gorée a préservé une cohérence architecturale qui réunit les apports culturels les plus dissemblables - nordiques et méditerranéens, islamiques et chrétiens - pour les fondre dans une unité dictée à la fois par l'exiguïté de l'espace, l'exposition aux vents du grand large, l'homogénéité du matériau de construction et, enfin, peut-être surtout, les courants d'une histoire tourmentée qui avait fait de chaque demeure un entrepôt d'esclaves en même temps qu'une position de défense. Gorée offre une heureuse symbiose du passé et du présent, de l'histoire et du quotidien, de l'harmonie des formules visibles et de l'empreinte dramatique du souvenir. C'est pourquoi elle constitue désormais un de ces lieux uniques où peut se retremper la mémoire des jeunes générations d'Afrique et des Amériques, en même temps que se renouvellent les sources de leur inspiration. Un tel endroit, poursuit-il, s'il appartient à l'imaginaire vivant de l'Afrique et des Amériques, appartient, dans une égale mesure, à la 
conscience du monde. Il peut devenir une terre de méditation, un haut lieu de réflexion et de recueillement, où les hommes, plus conscients des tragédies de leur histoire, apprendront mieux le sens de la justice et celui de la fraternité ${ }^{73}$ ". Le discours, repris des rapports antérieurs des experts de l'UNESCO où « chaque demeure est un entrepôt d'esclaves " est donc accrédité officiellement par ledit organisme international et rejoint le récit de Joseph Ndiaye.

Sur le rôle et la place de Gorée dans la traite atlantique, Amadou Mahtar M'Bow ajoute : «Dans des caves humides et sombres, ou dans des cachots de torture pour ceux qui se révoltaient, les déportés séjournaient durant des semaines, dans l'attente du voyage sans retour. Là, au moment d'embarquer, chaque esclave était marqué au fer rouge, à l'emblème de son propriétaire. Puis les esclaves étaient entassés dans les cales, où beaucoup d'entre eux devaient périr avant l'arrivée à destination. Mais l'Amérique, dont la colonisation a été à l'origine de cette tragique déportation, allait être également le cadre de grandes luttes libératrices qui, peu à peu, y mettront fin. Préparée par le triomphe de la Révolution haïtienne à Vertières en 1803, et proclamée au Congrès de Vienne en 1815 , l'abolition officielle de la traite négrière produisit ses effets sur Gorée ".

\section{L'application du Plan de sauvegarde et de restauration (1980-2000)}

En 1981, sous la nouvelle présidence d'Abdou Diouf et toujours avec le soutien de l'UNESCO, l'effort de restauration et de préservation se poursuit. Plusieurs édifices sont ainsi restaurés et rénovés pour être affectés à de nouvelles fonctions. Outre la France, d'autres pays de la communauté internationale se mobilisent pour la restauration de quelques bâtiments ${ }^{74}$. Des travaux d'aménagement portent également sur la restauration du kiosque à musique, des fontaines et de la Batterie de l'Embarcadère, le pavage des rues principales, l'aménagement du marché des produits de l'artisanat et de la place des restaurants. En 1982, Pierre André Lablaude enregistre l'état d'avancement et la réception des premières restaurations et fixe le programme des travaux à venir, dont celui sur les études concernant la rénovation de l'ancien Palais du Gouverneur (Relais de l'Espadon) en équipement hôtelier ${ }^{75}$.

Localement, la mise en œuvre de la campagne de sauvegarde est confiée au Bureau d'architecture des Monuments historiques (BAMH) qui a parfois recours à l'expertise de l'Institut Fondamental de l'Afrique Noire (IFAN) pour la conduite des opérations de rénovation et de restauration du patrimoine architectural ${ }^{76}$ selon une direction bicéphale des travaux. Intervenant parallèlement à l'aménagement d'un nouveau Musée historique au Fort d'Estrée (1977-1989), l'anthropologue d'origine belge Guy Thilmans aurait opéré ainsi à la Maison des Esclaves, en 1981-1982, pour des travaux de restauration des façades de la Maison des Esclaves ${ }^{77}$. 
Figure 8

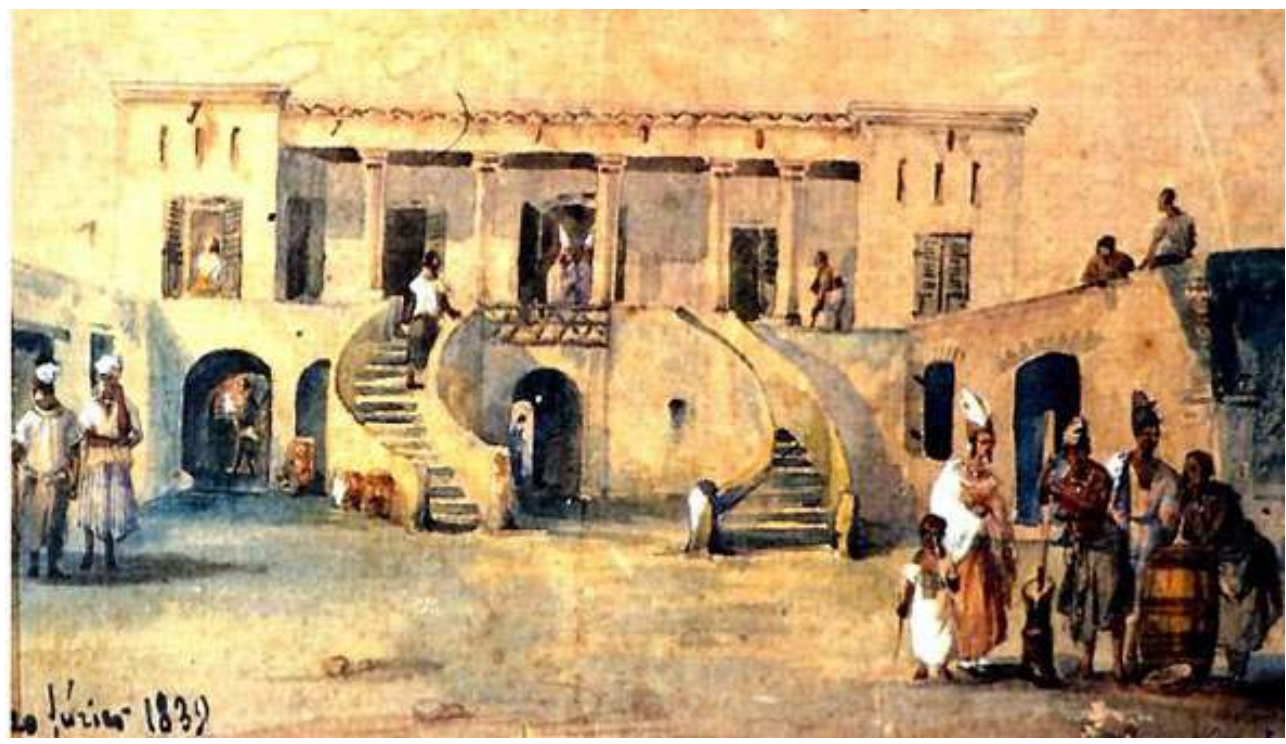

Vue de la cour intérieure de la Maison dite d'Anna Colas, actuellement Maison des esclaves. Aquarelle, Th. d'Astrel. En bas à gauche, date du 20 février 1839.

Phot. Coll. Xavier Ricou. (c) Xavier Ricou.

Figure 9

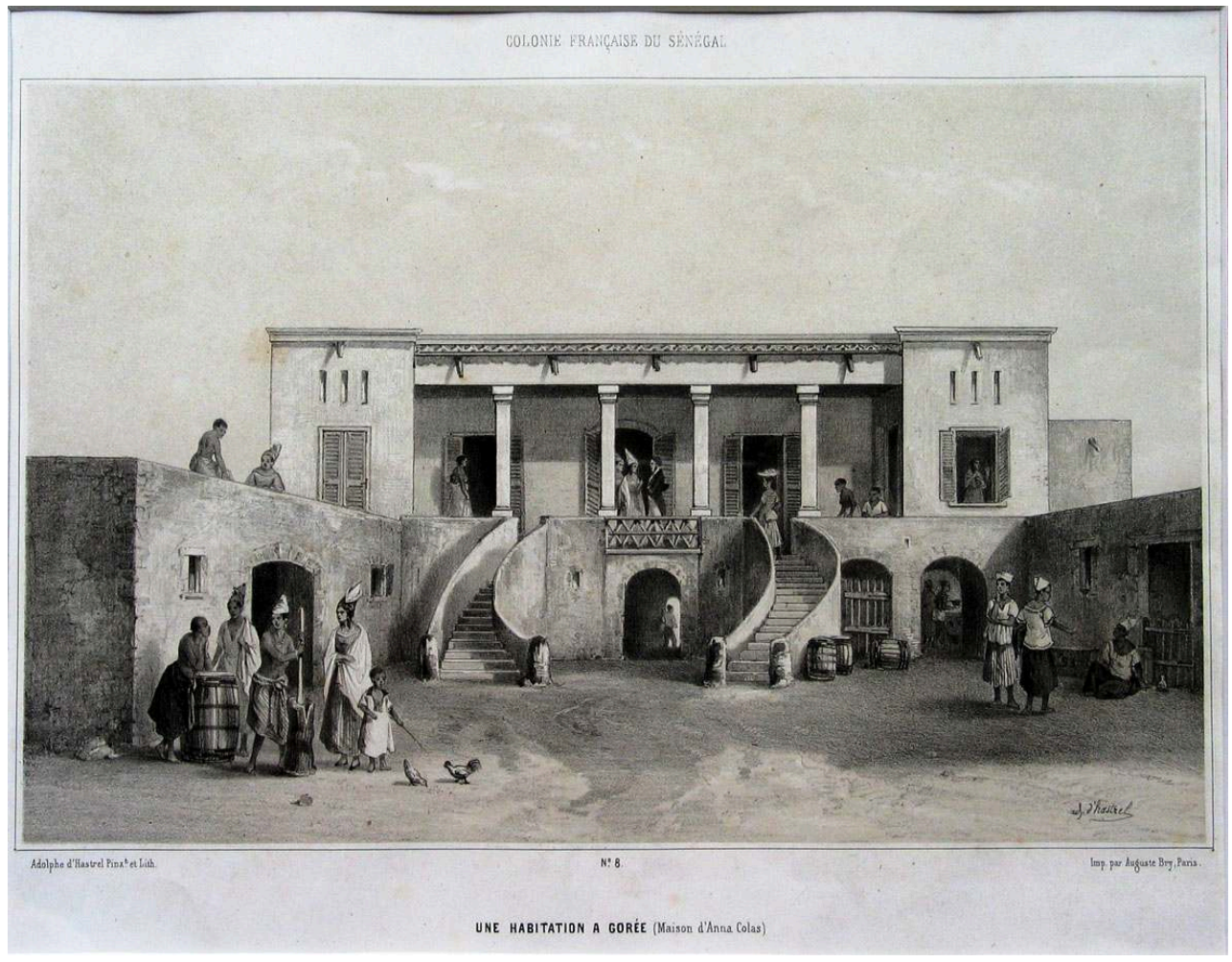

Vue de la cour intérieure de la Maison dite d'Anna Colas, actuellement Maison des esclaves. Lithographie par A. d'Astrel d'après l'aquarelle précédente (fig. n8). Extrait Colonie française du Sénégal. Paris, s.d. [vers 1848], pl. 8. 
Figure 10

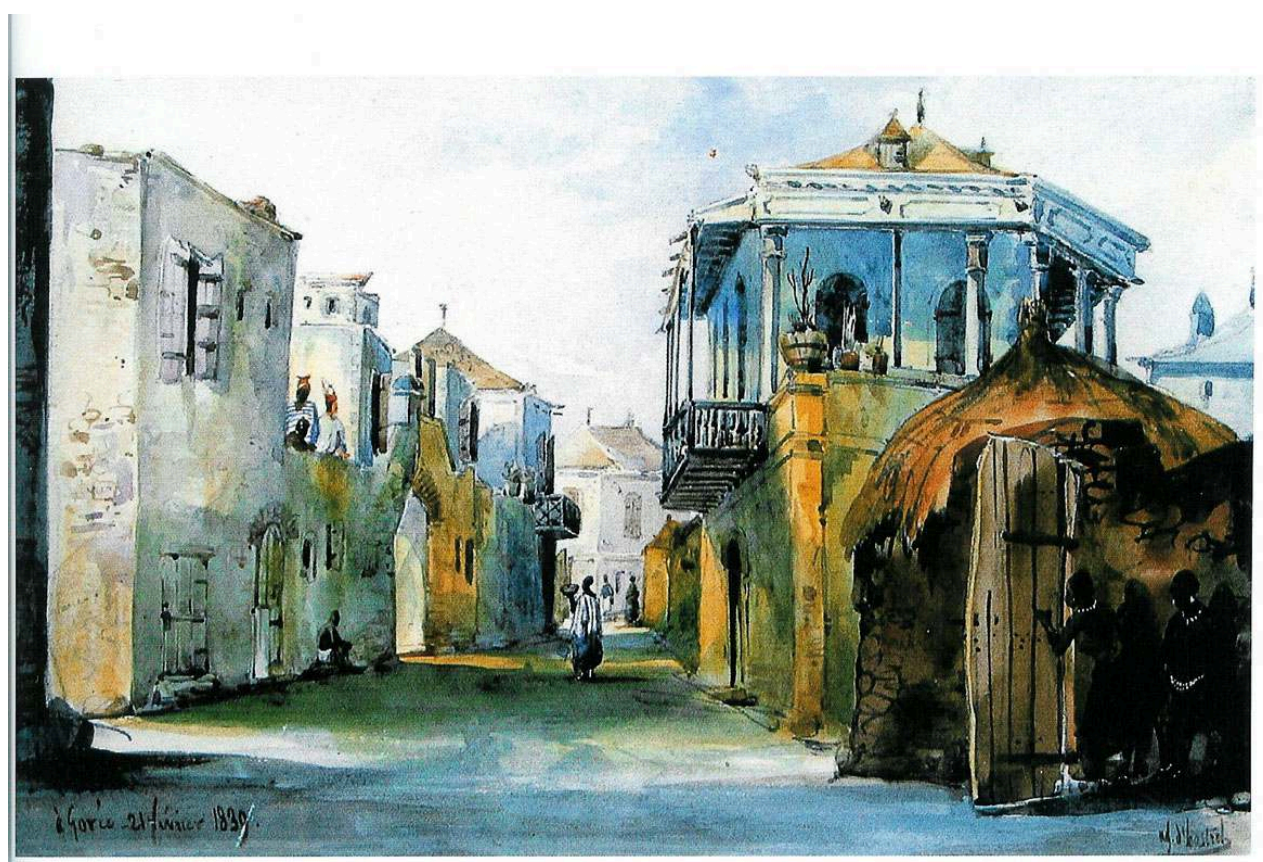

Maison Victoria Albis d'après une aquarelle de Hastrel.

Vue de l'actuelle rue Saint-Germain. À gauche, actuelle Maison des esclaves. Aquarelle, A. d'Astrel. En bas à gauche, date du 21 février 1839 .

Coll. Marie-José Crespin. (c) Marie-José Crespin.

Figure 11

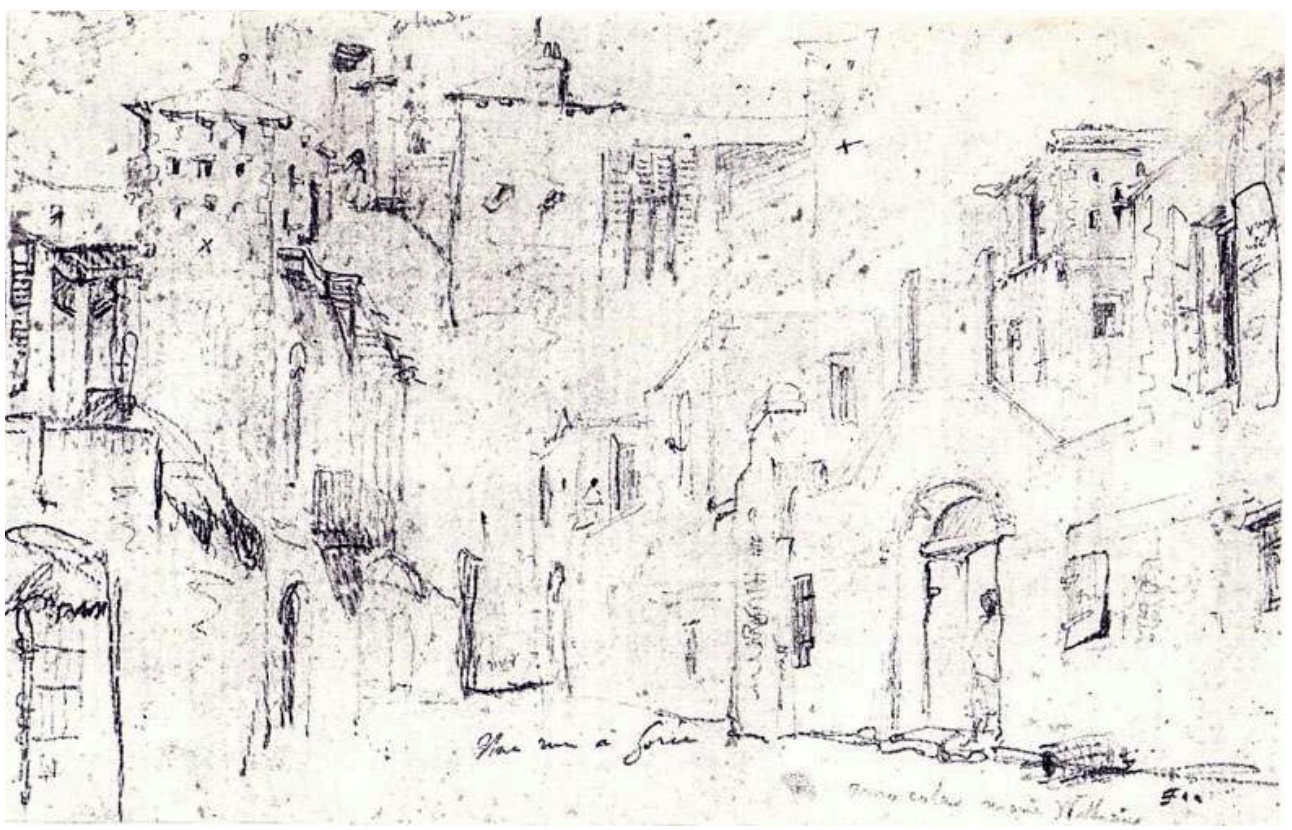

Revers de l'aquarelle précédente (fig. $n^{\circ}{ }^{10}$ ). Esquisse de la rue Saint-Germain, vue du côté opposé. Coll. Marie-José Crespin. (c) Marie-José Crespin.

Les manquements aux règles de restauration de l'UNESCO qui prônent un retour à l'authenticité, sont-ils dus aux campagnes de restauration du XIX et de la première moitié du XXe siècle, à celles de 1966, de 1981-1982, de 1990-199178 ou de 2010-2011 et 
aux difficultés d'adaptation d'une habitation privée en musée ouvert au public ? Malgré le manque de documentation et de relevés précis des états avant restauration, la comparaison entre les aquarelles d'Adolphe Hastrel de $1839^{79}$ (fig. $\mathbf{n}^{\circ} \mathbf{8}, \mathbf{9}, \mathbf{1 0}, \mathbf{1 1}$ ), les premières photographies et l'état actuel (fig. $\left.\mathbf{n}^{\circ} \mathbf{1 2}, 13\right)$ est édifiante. Pour l'expert Lablaude, la restauration en 1982 des chapiteaux de la galerie est effectuée selon « des proportions erronées et particulièrement maladroites... ${ }^{80}$ ». La disparition de la base des piliers de cette galerie et du garde-corps central au profit d'un mur plein est sans doute antérieure aux interventions des spécialistes. Mais la suppression des pièces des avant-corps latéraux avec leurs fenêtres aux volets persiennés de couleur verte et leurs baies d'aération ainsi que la mauvaise proportion des cintres des baies du rez-dechaussée, l'augmentation du nombre des ouvertures sur les façades des bâtiments latéraux, et l'application d'un badigeon à l'ocre rouge soutenu qui a remplacé celui à la chaux, de couleur blanc cassé ou très légèrement ocré, semblent bien relever de campagnes plus récentes. Les façades actuelles portent les traces de nombreux changements. Côté rue, un édicule surmonte la porte d'entrée et toutes les baies ont subi de notables modifications. Côté mer, la constatation est identique : agrandissement de la terrasse supérieure, baies bouchées, percements d'ouvertures... jusqu'à la construction d'une terrasse sur les rochers, accessible à partir de la Porte du voyage sans retour qui aurait pour effet de prévenir l'érosion marine ${ }^{81}$. Enfin, il est vraisemblable que le toit en tuile à deux versants (fig. $\mathbf{n}^{\circ} \mathbf{1 4}$ ) a succédé à une terrasse recouverte par une chape en béton coquillier dénommée argamasse qui se laisse deviner par la présence des gargouilles d'évacuation des eaux, visibles en $1839^{82}$.

Figure 12

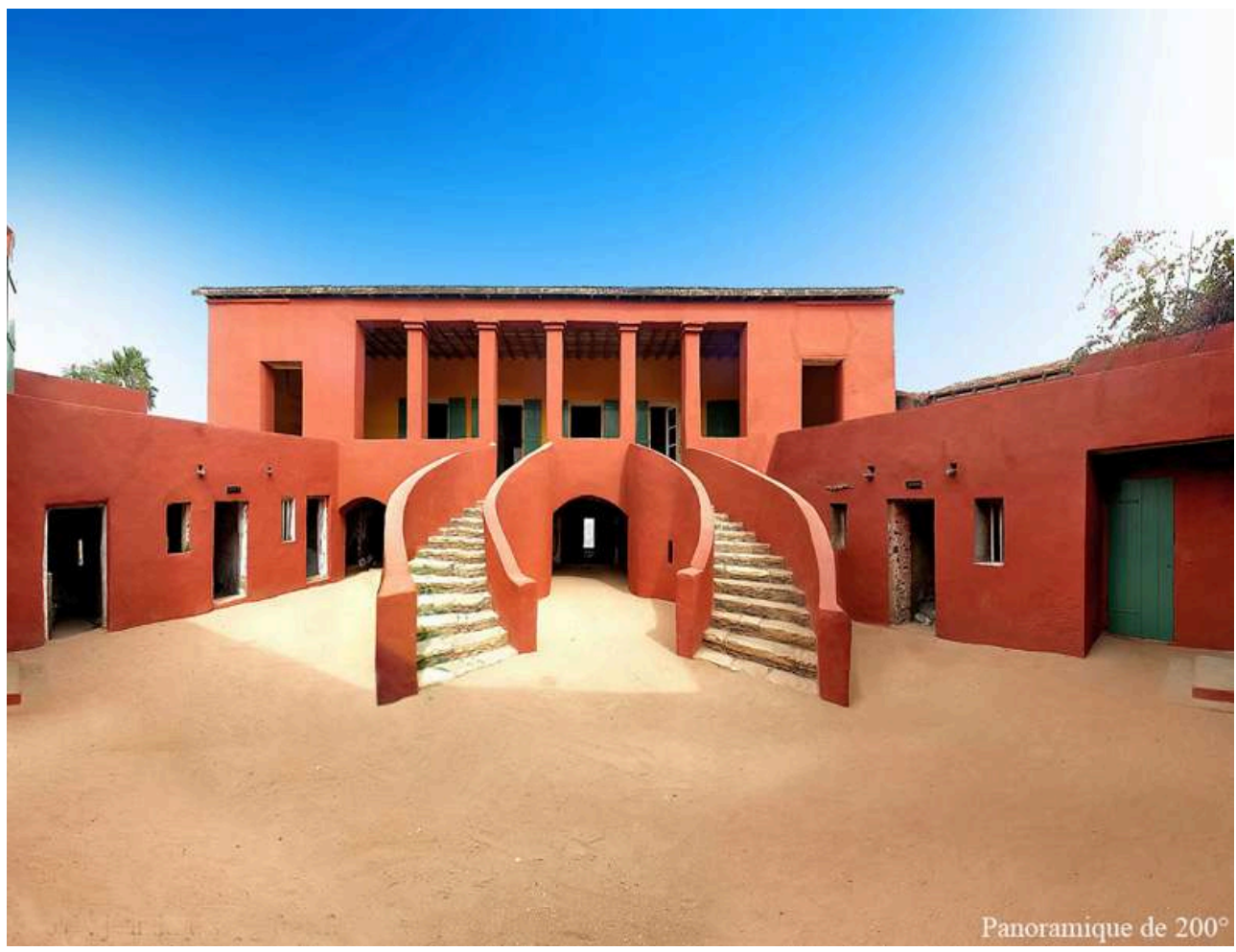

Cour intérieure de la Maison des Esclaves. Vue de l'entrée vers le logis. Prise de vue panoramique à $200^{\circ}$.

Phot. Jean Krausse, janv. 2011. (c) Jean Krausse. 
Figure 13

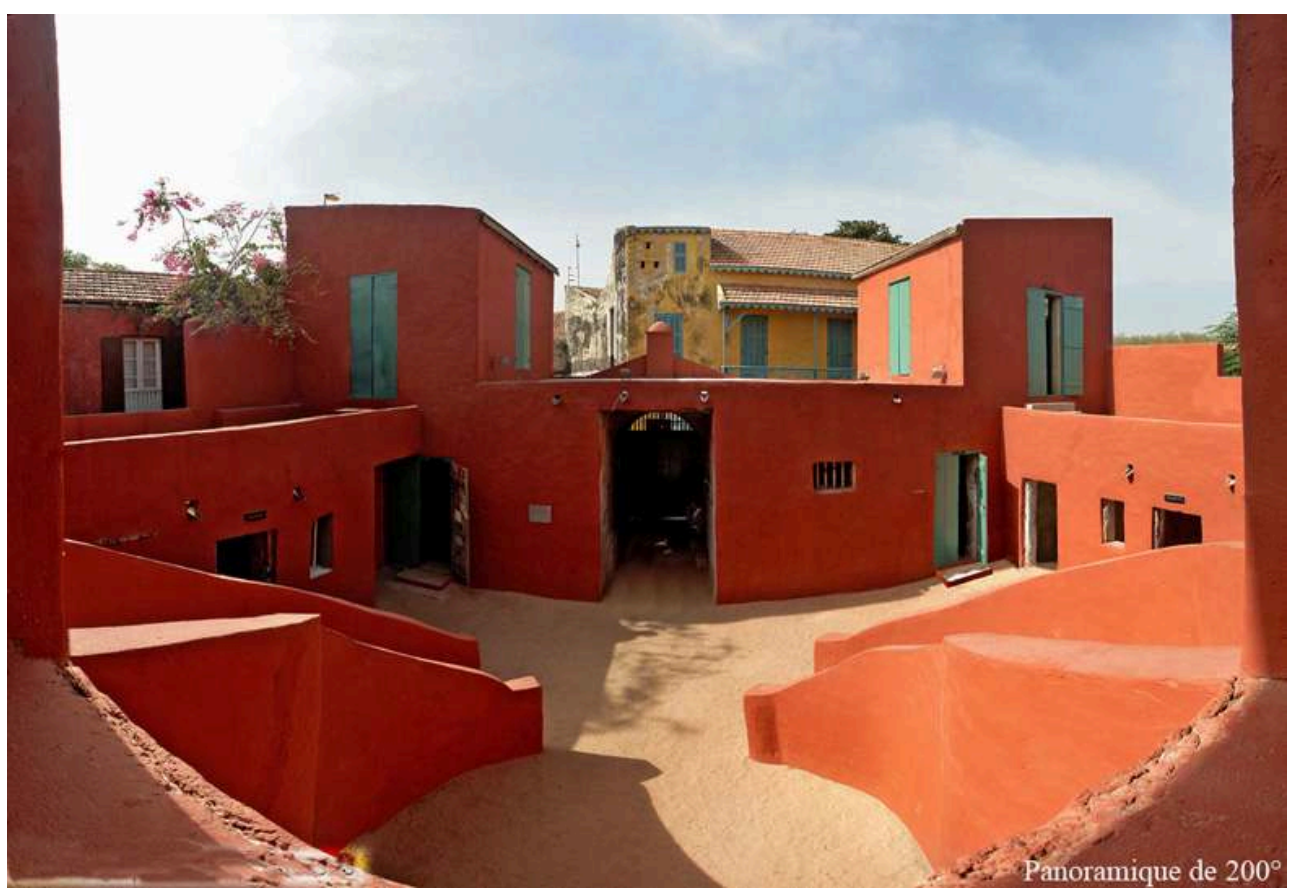

Cour intérieure de la Maison des Esclaves. Vue du logis vers l'entrée. Prise de vue panoramique à $200^{\circ}$.

Phot. Jean Krausse, janv. 2011. () Jean Krausse.

Figure 14

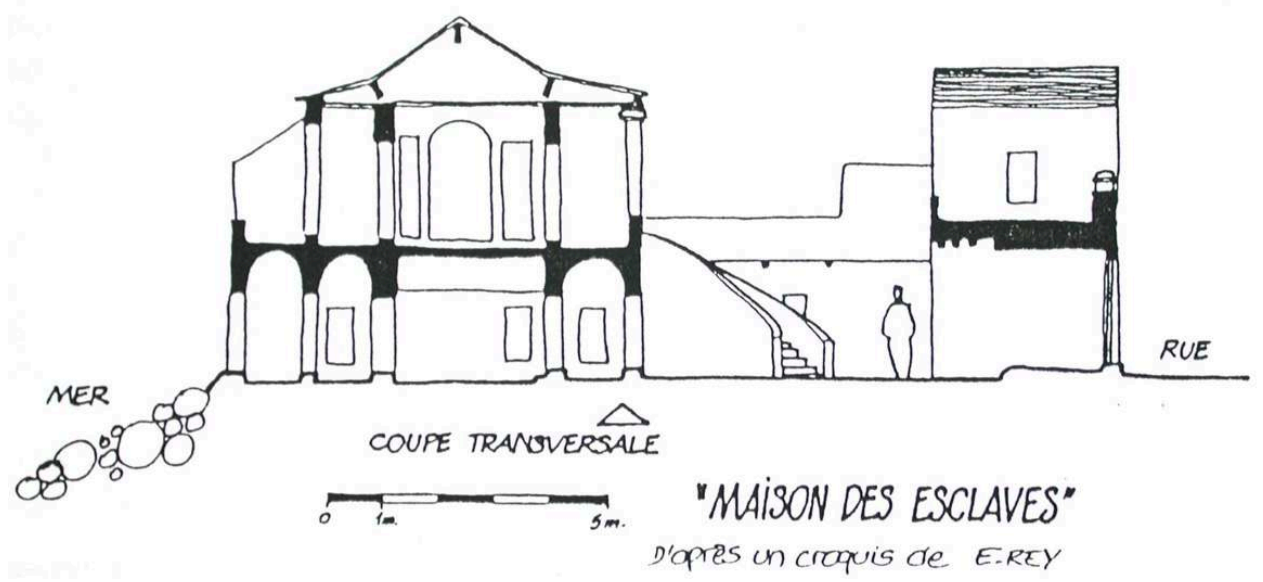

Coupe transversale de la Maison des Esclaves, par E. Rey, s.d. [vers 1982 ?].

Archives Direction du patrimoine classé, Gorée.

En 1992, dix ans après le lancement de la campagne internationale de sauvegarde, l'UNESCO publie un article sur "Gorée, l'île aux esclaves ", dans lequel on peut lire que trois bâtiments seulement ont été restaurés et qu'un quatrième est en cours de consolidation $^{83}$. Les différents examens de l'état de conservation de l'île menés par le Comité du patrimoine mondial depuis les années 1990 évoquent les travaux réalisés et ceux en cours, et félicitent régulièrement les autorités sénégalaises de leur implication ; 
mais ils soulignent aussi certains problèmes comme l'occupation illégale et anarchique du site du Castel, toujours préoccupante aujourd'hui et à l'origine d'innombrables désordres architecturaux qui menacent l'authenticité et l'intégrité du site. La $27^{\mathrm{e}}$ session du Comité signale qu'entre 2000 et 2001 le site a subi une pression d'aménagement urbain causée par un projet de construction hôtelière dont les travaux furent interrompus avant la modification irréversible du site ${ }^{84}$. À cette occasion, un souci récurrent est évoqué. Les lacunes de gestion seraient imputables à l'absence d'un gestionnaire basé sur l'île. La nomination d'un gestionnaire du site, recommandée par l'UNESCO pour tous les sites du patrimoine mondial, conformément aux articles 4 et 5 de la Convention de 1972, est effective depuis deux ans.

Au programme initial sur le Plan de sauvegarde de Gorée, lancé en 1980, l'île de Gorée va bénéficier indirectement d'un autre programme de l'UNESCO sur «La Route de l'esclavage ».

\section{"La Route de l'esclave », un nouveau programme de I'UNESCO (1995)}

Depuis 1994, un programme conjoint avec l'Organisation Mondiale du Tourisme (OMT) est lancé à Ouidah (Bénin): "La Route de l'esclave», une des multiples routes interculturelles de l'UNESCO lancées par le sénégalais Doudou Diene, alors directeur de la Division du dialogue interculturel et interreligieux ${ }^{85}$. L'objectif de ce programme est l'identification, la restauration et la promotion des sites, bâtiments et lieux de mémoire de la traite négrière qui jalonnent le parcours de la traite. Tout en privilégiant le tourisme culturel, ce programme représente un véritable enjeu de mémoire, car il intègre la dimension économique, historique et éthique du tourisme.

En 2004, dans le cadre du lancement de l'année internationale de la commémoration et de la lutte contre l'esclavage et de son abolition, le Directeur général de l'UNESCO situe ce devoir de mémoire : «Institutionnaliser la mémoire, empêcher l'oubli, rappeler le souvenir d'une tragédie longtemps occultée ou méconnue et lui restituer la place qui doit être la sienne dans la conscience des hommes, c'est en effet répondre à un devoir de mémoire ${ }^{86}$ ". L'UNESCO s'engage à institutionnaliser la mémoire pour empêcher l'oubli et vulgariser l'histoire de l'esclavage à travers différentes manifestations commémoratives : journées du souvenir, activités de remémoration et de vulgarisation, colloques, festivals, séminaires, ateliers, mémoriaux, expositions. En 2005, l'UNESCO publie une étude sur la mise en tourisme des sites liés à la traite négrière et à l'esclavage en Sénégambie ${ }^{87}$.

Dans le cadre de ce programme, la promotion de Gorée est largement soutenue par les autorités sénégalaises. Ainsi, en 2001, le musée maritime de Liverpool ${ }^{88}$ organise une exposition au musée de la Maison des Esclaves, considérée comme une "esclaverietémoin ». Cette exposition sur la Traite, réalisée en collaboration avec la Direction du Patrimoine historique du ministère de la Culture du Sénégal, par l'ambassade de Grande-Bretagne au Sénégal, est financée par le British Council et Shell Sénégal ${ }^{89}$. En 2006, on retrouve encore la Direction du Patrimoine historique qui parraine au Village des Arts de Dakar une exposition de l'artiste plasticien Lamine Barro sur « Gorée sur la route de l'esclavage, de la mémoire au pardon ${ }^{90}$. 


\section{Le mémorial de Gorée-Almadies (1996-2011)}

Ce programme sur La Route de l'esclave va sans doute faciliter l'éclosion finale du vieux projet sénégalais de construction d'un mémorial (toujours en attente de réalisation en 2011). Les autorités sénégalaises nourrissaient depuis longtemps l'idée d'ériger un monument en souvenir de la traite des esclaves. Dès 1975, lors d'une visite en Martinique, le président Senghor avait invité les artistes de la communauté afroaméricaine à l'édification d'un monument en hommage à l'Afrique ${ }^{91}$. Le projet de monument à ériger sur l'île de Gorée devait être un trait d'union entre l'Afrique et sa diaspora. Ce monument symboliserait le départ des Africains vers les Amériques en jetant un pont entre les deux continents. Il devait se présenter sous la forme d'« un groupe de personnes qui semblent se lever au-dessus du socle de la sculpture comme pour lancer un appel à ceux qui sont partis à bord des bateaux négriers; à l'autre extrémité se dresse un homme qui, lui, semble crier : Afrique, lève toi ! Toi, Nègre de là-bas, rejoins-nous!92 ".

En 1986, le président Abdou Diouf reprend le projet d'érection d'un mémorial dédié à l'Afrique et à sa diaspora. Il soumet officiellement l'idée de réaliser un projet de dimension internationale lors $\mathrm{du}$ sommet historique de l'Organisation de l'Unité Africaine (OUA) à Addis Abéba. Cinq ans plus tard, une Fondation est créée auprès du ministère de la Culture du Sénégal, présidée par l'ancien directeur général de l'UNESCO, le sénégalais Amadou-Mahtar Mbow pour coordonner les actions internationales de promotion et rechercher les financements. Le 29 juin 1992, la première pierre du Mémorial Gorée-Almadies est posée par le président de la république du Sénégal, à l'occasion du $28^{\mathrm{e}}$ sommet de l'OUA et en présence notamment de Federico Mayor, directeur général de l'UNESCO. Ce geste permet de dynamiser à nouveau la campagne pour la sauvegarde de Gorée lancée par l'UNESCO dix ans plus tôt, de répondre aux sollicitations de nombreux intellectuels, artistes et intellectuels noirs, notamment ceux du continent américain. Le choix du site des Almadies se justifie par sa position avancée sur l'Atlantique, orientée en direction des communautés noires américaines vivant de l'autre côté de l'Océan et le désir de ne pas entacher l'environnement de l'île (où il est quand même prévu dès l'origine d'ériger une réplique...). L'UNESCO inscrit ce projet dans le programme sur la Route de l'Esclave, ce qui devait faciliter la recherche de financements internationaux.

En 1996, un concours international pour la construction de ce mémorial est lancé. Le cahier des charges est préparé par l'International Union of Architects (UIA) qui organise un concours international d'architecture. Deux cents quatre-vingt dix concurrents de 66 pays (au total 900 dossiers) participent au concours. Le programme, d'une surface d'environ $12000 \mathrm{~m}^{2}$, portait sur la conception du mémorial, d'un musée dédié à la navigation, d'un centre d'études et de recherche doté des équipements les plus performants et d'une structure administrative. Les espaces verts devaient faire l'objet d'un traitement spécifique, notamment celui d'un circuit de visite " la procession des civilisations ", partie intégrante du lieu ${ }^{93}$.

Le lauréat désigné en novembre 1997 est l'architecte italien Ottavio Di Blasi ${ }^{94}$. Il a été choisi par un jury réuni à Dakar sous la présidence de Harry G. Robinson III, viceprésident de l'Université Howard de Washington (États-Unis) et représentant du Directeur général de l'UNESCO. «Le projet du lauréat reflète l'esprit, la voix et le symbolisme de l'Afrique. Par sa forme africaine authentique et puissante, il exprime 
une identité clairement lisible, tant pour le Musée que pour le mémorial. La relation avec la mer s'établit par l'ancrage de l'élément dominant du programme (l'aiguille) sur la falaise et la position de l'autre élément (la coque) sur pilotis au-dessus de la mer. La fracture créée par ce contraste est l'élément majeur de l'approche qui a présidé à la conception du projet. La structure de modules en nid d'abeilles est l'élément typologique dominant. Un système mécanique est intégré à la construction et conçu pour réduire les effets du soleil. La mer est utilisée pour abaisser la température de l'air ambiant ${ }^{95}$ ». Après avoir été exposée à Dakar, la maquette restera longtemps au siège de l'UNESCO à Paris. Ce mémorial - nouvelle " arche d'alliance » pour le président Abdou Diouf - honore la mémoire des victimes de la traite négrière et symbolise la tolérance et le dialogue entre les civilisations ${ }^{96}$.

Malgré des appels répétés à la mobilisation internationale, la Fondation ne trouve pas les finances nécessaires à sa réalisation, estimées à 60 milliards de francs $\mathrm{CFA}^{97}$. Le président Diouf inaugure rapidement le 31 décembre 1999 une réplique réduite, perchée sur le sommet de l'île de Gorée (fig. $\mathbf{n}^{\circ}{ }^{15}$ ). Le coordinateur du projet est le poète Amadou Lamine Sall, aidé par l'architecte du BAMH Mamadou Berthet et l'ingénieur Mamadou Lamine Adama Diallo, avec l'entrepreneur Fougerolles. La présence de cette réplique, sur le site du Castel de Gorée, projetée dès l'origine du projet, est remise en cause au lendemain des élections présidentielles par le nouveau ministère de la Culture. En 2010, l'UNESCO déclare que «la réplique du mémorial de Gorée sur le Castel est un exemple éloquent de ce qu'il ne faut pas faire pour la préservation de l'intégrité du site et d'un commun accord avec l'UNESCO, il a été convenu de procéder à la requalification de cet ouvrage ${ }^{98}$ ».

Figure15

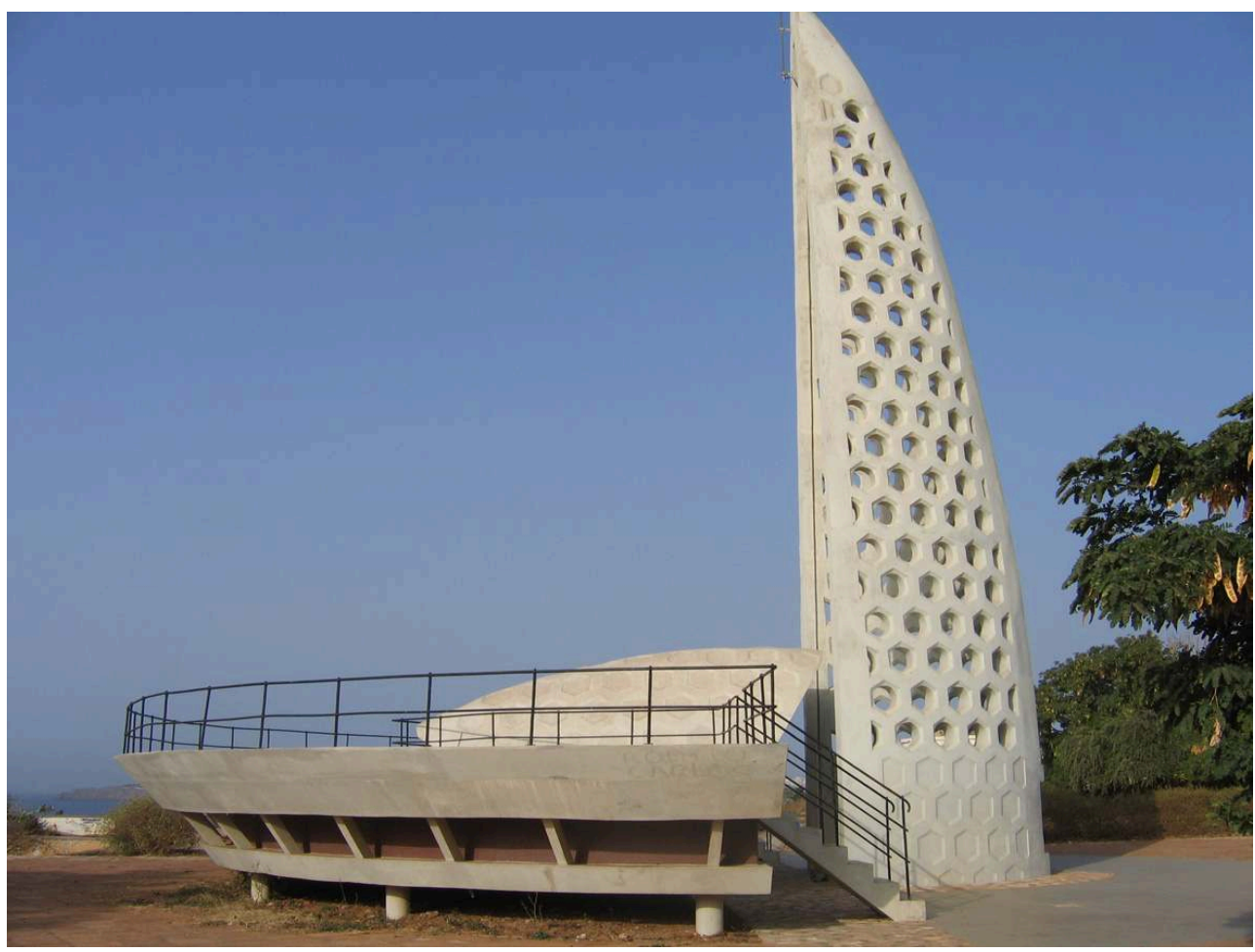

Gorée, réplique du mémorial.

Phot. B. Toulier, fév. 2007. ( ) B. Toulier. 
Parmi les nombreux projets en cours, il faut signaler un projet de construction pour un nouveau mémorial de Gorée "en hommage à des millions d'Africains enlevés " qui réapparaît en avril 2011, un an avant les nouvelles élections présidentielles ${ }^{99}$. Le projet, promu par le groupe financier Swist Invest, est signé d'un architecte-designer tchèque Martin Guadev ${ }^{100}$, aidé par le studio Sipek. Il reprend une partie du programme du concours UIA/UNESCO de 1996, avec des références post-modernes plus explicites. Le bâtiment d'accueil est une réplique de la Maison des esclaves de Gorée et le visiteur est conduit par la « porte du voyage sans retour » sur une jetée formée par un navire prêt à appareiller, aux cales chargées d'esclaves enchaînés. On retrouve comme commissaire à sa réalisation Amadou Lamine Sall, avec l'architecte Mamadou Berthet et de nouvelles personnalités comme le sculpteur Ousmane Sow. À ce jour, ce projet diffusé sur internet et régulièrement agité n'a pas connu un début de réalisation malgré un tapage médiatique constant ${ }^{101}$.

\section{Pour une cohérence des discours muséaux sur la traite atlantique}

L'indépendance du Sénégal marque l'accroissement des institutions muséales sur l'île. Le musée historique de l'IFAN est déplacé au fort d'Estrée à partir de 1977. Son précédent emplacement était trop exigu pour permettre sa transformation en une institution muséale à la mesure du grand dessein qui prend forme à cette période. Le président Léopold Sédar Senghor lui affecte la batterie de la pointe Nord (fort d'Estrée), à la demande du professeur Amar Samb, directeur de l'IFAN. Les travaux de restauration $\mathrm{du}$ fort d'Estrée sont supervisés par le Bureau d,Architecture des Monuments Historiques (BAMH) ${ }^{102}$. La restauration et l'aménagement muséographique sont réalisés par Guy Thilmans, chercheur à l'IFAN ${ }^{103}$. Cet établissement ne présente plus l'histoire de l'Afrique occidentale comme précédemment, mais se concentre sur la seule histoire du Sénégal, de la Préhistoire aux royaumes qui ont précédé la présence française, en passant par la traite des noirs et les résistances anti-coloniales (fig. $\left.\mathbf{n}^{\circ} \mathbf{1 6}\right)$. Il ouvre en 1989. 


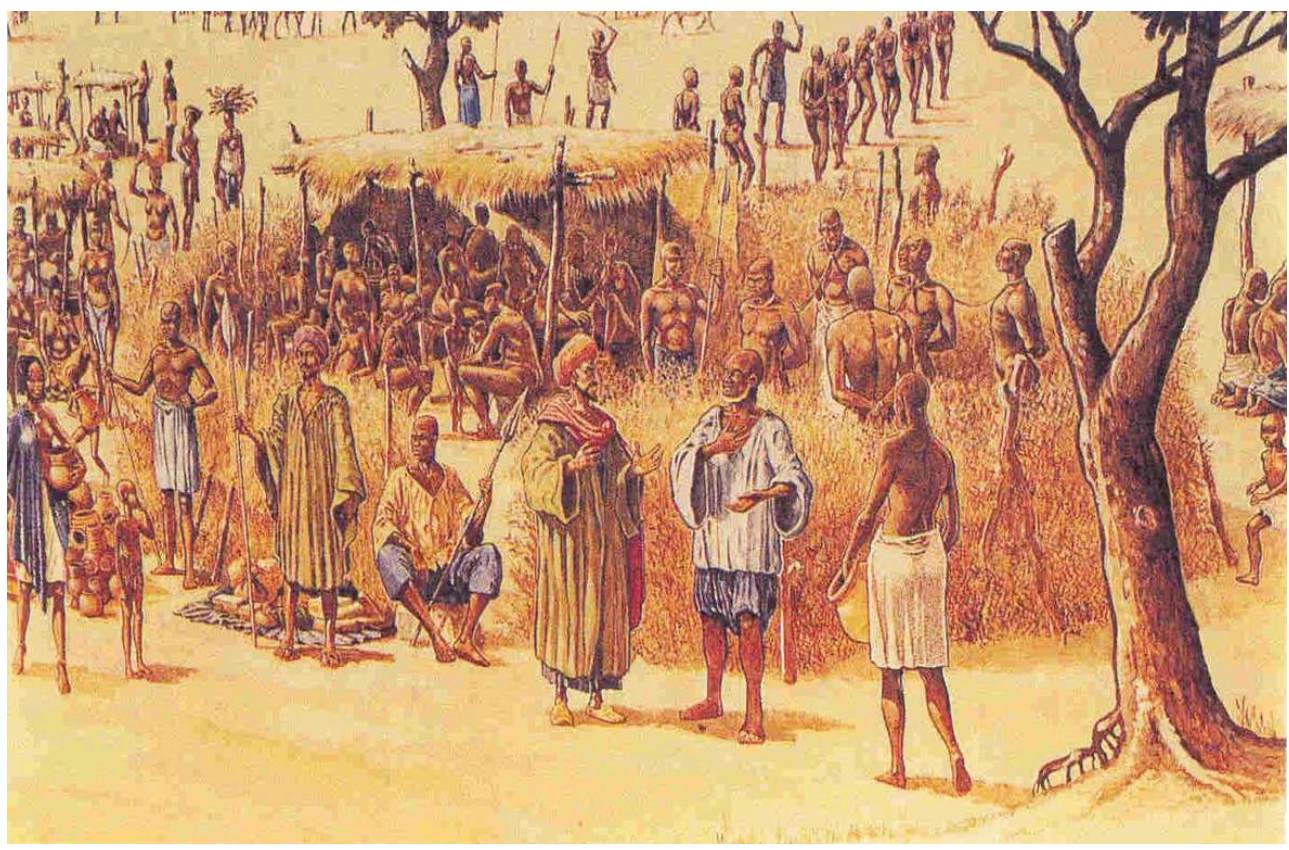

Gorée, musée historique, traite transaharienne, peinture murale, salle 5. Extrait : CAMARA, Abdoulaye et BENOIST, J. R. de. Gorée, Guide de lîle et du Musée historique. Publication du Musée historique, Dakar, avril 1993, p. 5.

En face de la Maison des Esclaves, dans l'ancienne villa de la riche signare Victoria Albis, est installé le premier musée dédié aux femmes sur le continent africain ${ }^{104}$. Ce musée privé, le premier sur l'île de Gorée, est issu d'un projet conçu dès 1987 par le cinéaste Ousmane William Mbaye à la suite de plusieurs expositions de diverses productions artisanales, économiques et culturelles d'associations sénégalaises. Ouvert en 1994 sous la direction d'Annette Mbaye d'Emeville, on y trouve des objets usuels, des outils agricoles, des instruments de musique, des poteries, des vanneries, ainsi que des photographies permettant de mieux comprendre la vie quotidienne de la femme dans le pays. Le musée est sous le parrainage posthume d'Henriette-Bathily ${ }^{105}$. C'est aussi un centre d'apprentissage, où les femmes viennent s'éduquer, recevoir une formation à l'artisanat et travailler ${ }^{106}$.

Le musée de la mer ${ }^{107}$, aménagé dans une ancienne maison de la compagnie des Indes du XVIII ${ }^{e}$ siècle, est rénové en 1995. À cette occasion, le laboratoire de biologie marine est déménagé, en partie, à l'IFAN Cheickh Anta Diop. Aujourd'hui, le bâtiment central abrite les expositions, tandis que le bâtiment secondaire conserve les cuves et les spécimens laissés sur place lors du déménagement du laboratoire. Ce dernier fait office de laboratoire de conservation. Le musée offre une plus grande place à l'homme dans ses relations avec la mer: la mer source de vie, mais aussi source d'événements dramatiques. Il a pour mission de promouvoir la connaissance de la mer, de ses facteurs et de ses fonctionnements, et de sensibiliser à la préservation de l'environnement marin ${ }^{108}$. Aujourd'hui le musée est à nouveau fermé en raison d'une forte dégradation. Les efforts sont en cours avec de nombreux partenaires pour le financement de sa réhabilitation ${ }^{109}$.

À partir de ce bilan sur les musées de Gorée, l'actuelle direction du patrimoine recherche aujourd'hui une meilleure cohérence et un discours plus adapté à l'îlemémoire de la traite atlantique. Cet esprit de témoin vivant de la mémoire de 
l'esclavage qui se retrouve à la Maison des Esclaves pourrait être relayé dans les autres structures muséales présentes sur l'île afin de clarifier les relations entre mémoire de l'esclavage et mémoire de la traite atlantique, entre les esclaves qui restaient à Gorée et les captifs qui partaient en Amérique. Sans pour autant modifier leurs thématiques actuelles, les autres structures pourraient évoluer vers une plus grande imprégnation dans l'ambiance des mémoires de la traite atlantique. La désaffection relative des autres musées, par rapport à la Maison des Esclaves, semblerait plutôt être un problème de perception des attentes de la part des visiteurs qu'un problème d'incohérence du discours intrinsèque. Ce problème pourrait être résolu par un effort d'adaptation qui, dans chacune des structures existantes, a déjà une base bien réelle. Le musée de la femme Henriette-Bathily développe un discours sur la femme africaine (son rôle social, économique, culturel et politique). La fonction d'animation et la portée sociologique sont indéniables. Cependant, bien que situé sur le lieu de mémoire de la traite atlantique, celui-ci traite trop marginalement de la condition de la femme dans la traite. Il serait peut-être souhaitable, toujours d'après la direction du Patrimoine au vu de l'importante documentation existante sur la femme, de sa captivité au voyage sans retour, et jusqu'à ses conditions de vie dans les plantations, de développer un peu plus ce discours pour se renouveler et être plus en conformité avec les attentes des visiteurs.

Réputé pour sa collection de 750 espèces de poissons et 700 espèces de mollusques, le musée de la mer présente également les écosystèmes et l'habitat de la région. Bien que son discours muséographique parle aussi de la traversée, la vocation première de laboratoire de recherche avec ses remarquables collections de biologie marine n'a pas pu s'accommoder avec la vocation muséale de la traite développée à Gorée, et l'écart est devenu de plus en plus important depuis que Gorée est inscrite au patrimoine mondial. Pour cela, la direction propose de dissocier les deux axes muséographiques en concevant un centre pour le laboratoire de recherche de l'IFAN Cheikh Anta Diop, et un musée centré sur la traversée, les navigations en général y compris en Afrique, les conditions de la traversée et la vie dans les cales des bateaux négriers. Devant la porte du voyage sans retour de la Maison des Esclaves, un projet d'installation d'une cale grandeur nature d'un bateau négrier, serait à l'étude.

Enfin, le musée historique présente l'histoire du Sénégal. De ce fait, il documente assez bien certains épisodes de la traite. Pour autant, le discours muséographique sur le passé de la nation semblerait trop ambitieux pour demeurer à Gorée. Des réflexions sont aujourd'hui en cours pour doter le Sénégal d'un véritable musée national à Dakar. Quant au musée de Gorée, la direction du patrimoine pense qu'il devrait se concentrer sur la présentation exhaustive et illustrée de la production historique, documentaire et archivistique sur la traite atlantique. Ce musée pourrait aussi aider à rendre l'image de Gorée plus conforme à la diversité qui régna en ces lieux, en réalisant des fresques et des reconstitutions sur la vie de la population goréenne.

Le discours symbolique, forgé dès l'époque coloniale à partir d'une "Maison des Esclaves » et d'une "porte du voyage sans retour», repris et amplifié par Joseph Ndiaye, doit être progressivement renouvelé. Comme à Ouidah et dans les autres lieux de célébration du pèlerinage de ce tourisme mémoriel, la «route de l'esclave » est jalonnée de représentations abstraites ou le plus souvent imagées ${ }^{110}$. La voile en béton d'un bateau négrier, dominant la réplique d'un grand mémorial avorté est érigée depuis 1999 au sommet de l'île-mémoire, malgré les protestations tardives de l'UNESCO. Une statue des esclaves libérés, offerte en 2003 par les Guadeloupéens pour célébrer l'abolition de l'esclavage, est aujourd'hui installée dans le jardin précédant l'accès à la 
Maison des esclaves (fig. $\mathbf{n}^{\circ} \mathbf{1 7}$ ). Les nouveaux projets en cours des mémoriaux et des musées renouvellent et amplifient le discours. Deux projets associent à cette " porte du voyage sans retour" de la Maison des esclaves ou de sa reconstitution, la représentation des cales d'un navire négrier avec leurs esclaves enchaînés. Les critères patrimoniaux d'authenticité et de respect de l'environnement, prônés par l'UNESCO risquent à nouveau de voler en éclat ${ }^{111}$.

Figure17

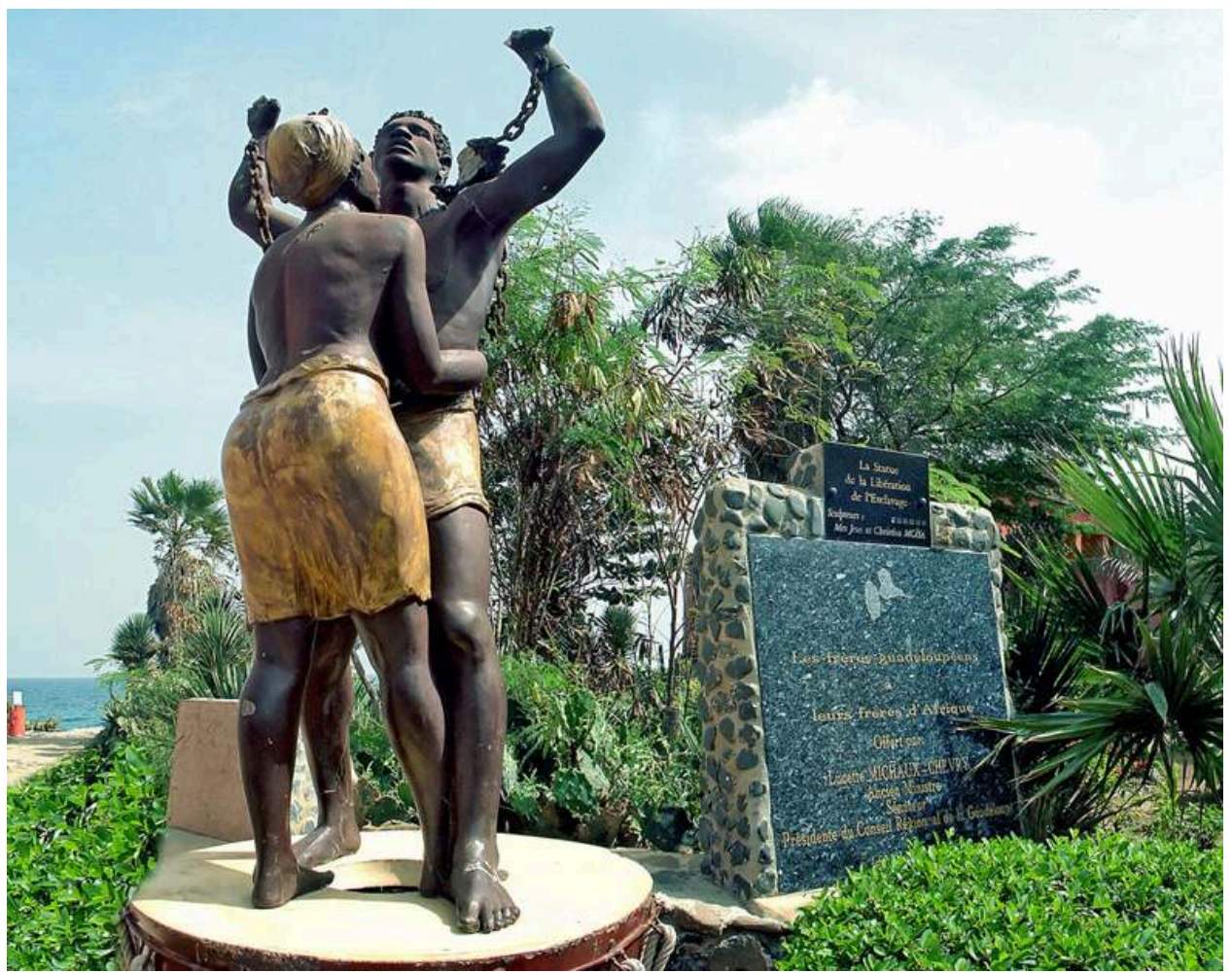

Gorée, statue symbolisant La libération de l'esclavage, par Jean et Christian Moïsa, 2002.

Phot. Jean Krausse, janv. 2011. (c) Jean Krausse.

Depuis plusieurs décennies, avant ou après l'Indépendance du Sénégal, l'île de Gorée est un forum permanent où le patrimoine, les mémoires et l'histoire ${ }^{112}$, les commémorations et les mémoriaux, les discours muséaux, les souvenirs et les représentations, imaginées, entretenues ou construites sur la Traite atlantique sont soumis à une remise en cause perpétuelle, s'adaptant aux découvertes et aux connaissances historiques et aux messages culturels, idéologiques et politiques délivrés par les communautés patrimoniales, l'État du Sénégal et l'UNESCO.

L'histoire de l'esclavage et de celle de la traite atlantique à Gorée, qui ne se limite pas à l'histoire d'un simple «échange commercial» entre producteurs et acheteurs dans un temps donné, inclut et dépasse l'histoire d'un passé raconté et la place de ce passé dans l'imaginaire présent des Sénégalais, c'est-à-dire ce "présent du passé » qu'est la mémoire, collective, sur lequel prend appui une grande partie du patrimoine ${ }^{113}$. 


\section{NOTES}

1. - Nous remercions Ibrahima Thioub, Xavier Ricou, Cyr Descamps et Dominique Moiselet pour leur aide précieuse dans l'élaboration de cet article. L'article, terminé en décembre 2011, ne tient pas compte des derniers développements de l'actualité et du résultat des recherches en cours. Voir notamment KANE, Moustapha. Histoire de la construction d'un lieu de mémoire de la traite atlantique des esclaves : Gorée de 1944 à nos jours. Dakar, UCAD.

2. - Inscription relevée sur une plaque érigée le 8 novembre 1999 à Gorée à l'entrée du jardin de plantes grasses «canarien » par la Maison africaine de la poésie internationale en présence du Président de la République du Sénégal et du Premier Ministre du Canada.

3. - GUEYE, Mbaye. L'esclavage au Sénégal du XVII ${ }^{e}$ au XIX ${ }^{e}$ siècle. Nantes, thèse de doctorat de $3^{\mathrm{e}}$ cycle, 1969 ; L'Afrique et l'esclavage. Une étude sur la traite négrière. Martinsart, 1983.

4. - DE ROUX, Emmanuel. «Le mythe de la Maison des esclaves qui résiste à la réalité ». Le Monde, 27 décembre 1996. SAMB, Djibril (dir.). Gorée et l'esclavage, Actes du Séminaire sur Gorée dans la traite atlantique : mythes et réalités, Gorée, 7-8 avril 1997. Dakar : IFAN-CAD, Initiations et Études Africaines, 38, juillet 1997.

5. - Les esclavages et les traites : communautés, frontières et identités. Pôle d'Excellence Régional (PER) domicilié au Département d'Histoire de la Faculté des Lettres et Sciences Humaines de l'Université Cheikh Anta Diop. http://peresclave.over-blog.com/categorie-10204481.html [consulté le 25/04/2011]. En 2011, le PER est devenu le Centre Africain de Recherches sur les Traites et les Esclavages (CARTE). http://www.carte-ucad.org/fr [consulté le 26/02/2013]. Sur la traite négrière et l'esclavage, voir notamment les orientations bibliographiques données par : le département d'histoire de l'Université Cheick Anta Diop de Dakar (UCAD), http://www.histoireucad.org/archives/index.php/remository.html?func=select\&id=34 [consulté le 25/04/2011]; l'UNESCO, http://unesdoc.unesco.org/images/0018/001887/188769m.pdf [consulté le 25/04/2011]. Pour un état des lieux et des savoirs sur Gorée, voir : CAMARA, Abdoulaye, BENOIST, Joseph-Roger (de). Histoire de Gorée. Maisonneuve et Larose, 2003, p. 153-155 (bibliographie). Un inventaire du patrimoine immobilier de Gorée, conduit par la Direction du Patrimoine historique classé du ministère de la culture du Sénégal, est en cours depuis 2007.

6. - Voir le site : http://whc.unesco.org/fr/list/26 [consulté le 25/04/2011].

7. - Voir en Afrique les nombreux projets mémoriels et concurrentiels en oeuvre ou en gestation en Gambie, Ghana, Bénin, Congo, ... mis en oeuvre avec l'aide de l'UNESCO depuis 1994 : http:// www.unesco.org/africa/portal/culture_4.html [consulté le 26/02/2012].

8. - Guide du tourisme en Afrique Occidentale Française et au territoire du Togo sous mandat français.

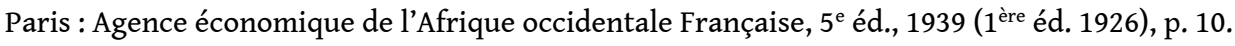

9. - « Au XVIII ${ }^{\mathrm{e}}$ siècle [...], l'Afrique [...] fournit la main d'œuvre esclave nécessaire à l'exploitation des Îles de l'Océan Indien, des Antilles et de l'Amérique. Il y a là un transport de force odieux mais tout à fait méconnu. Les philosophes blâment l'esclavage et la traite mais tout en accréditant la légende du sauvage africain heureux dans sa vertueuse sauvagerie et tout en profitant d'une civilisation matérielle qui comprend les produits coloniaux, ils ne mettent pas l'Afrique à l'honneur du travail. Et il faudra encore de longues années pour que l'on découvre, sous les préjugés négriers et sous les rêveries humanitaires, le caractère paysan des hommes de la savane. ». Guide du tourisme en Afrique Occidentale Française et au territoire du Togo sous mandat français. Paris : Agence économique de l'Afrique occidentale Française, $5^{\mathrm{e}}$ éd., 1939 (1 ${ }^{\text {ère }}$ éd. 1926), p. 9.

10. - «L'œuvre de la France en Afrique Occidentale ». L'Illustration, 29 février 1936, 94 ème année, n4852, p. 253-256 et supplément p. XIII-XXV. Description de « l'île des esclaves », p. 257-258. 
11. - Le 31 mai 1936, la compagnie Air-France inaugure son premier service hebdomadaire entre la France et le Sénégal en trimoteur Dewoitine 338. Ces avions transportaient 15 passagers à la vitesse de $275 \mathrm{~km} / \mathrm{h}$. Cette remarquable aventure humaine et technologique participe également du patrimoine en partage entre la France, l'Afrique et l'Amérique. Pour cette raison, le Sénégal a introduit l'Aéropostale sur sa Liste indicative en vue d'une inscription sur la liste du patrimoine mondial de l'UNESCO dans la catégorie des biens en série.

12. - Renseignement aimablement communiqué par Xavier Ricou (avril 2011).

13. - Guide du tourisme en Afrique Occidentale Française et au territoire du Togo sous mandat français.

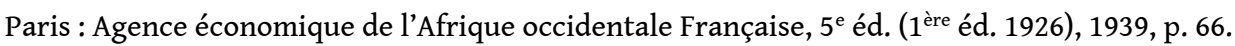

14. - L'Illustration, $n^{\circ} 4435,3$ mars 1928. Renseignement aimablement communiqué par Xavier Ricou.

15. - BRAU, P. (Dr). «L'île du sortilège ». Bull. Comité d'Études historiques et scientifiques de l'Afrique Occidentale Française, t. XI, n 4, oct.-déc. 1928, tiré à part, p. 63.

16. - GAFFIOT, Robert. Gorée, capitale déchue. Paris : L. Fournier, 1933, p. 93. GAFFIOT, Robert. Gorée, toute petite île. Arc-et-Senans : Éditions de l'Aile, 1933, p.11. Dessin portant la légende : "Cour d'une ancienne maison négrière ». Ce dessin, signé de la main de l'auteur Robert Gaffiot (R.G.), représente la cour de l'actuelle Maison des Esclaves. Il ne porte pas [encore] son appellation postérieure qui serait donc apparue entre 1933 et 1936. Dans ses deux ouvrages Gaffiot n'emploie pas l'expression de " porte de non retour ", l'auteur ne précise pas s'il s'agit de la reprise d'une «tradition », orale ou écrite antérieure.

17. - CARIOU, Pierre-André. Promenade à Gorée (Sénégal), manuscrit dactylographié, 1951-1952. L'auteur dépose trois exemplaires du manuscrit à Paris: aux Archives d'Outre-Mer, à la Bibliothèque nationale de France et aux Archives de la Marine. Aujourd'hui, l'exemplaire des Archives de la Marine est conservé à la bibliothèque des Archives d'Outre-Mer à Aix-en-Provence (CAOM) : - copie du manuscrit provisoire, [s.l.n.d.] [dactylographié], (288-6 p.). Aix-en-Provence : Centre des Archives d'Outre-Mer, 24Miom/57 ; - [s.l., s.n.] 1978, 1 vol. (274, 64, [19], 12) : nombr. pl. h. t., plans et cartes h. t. et dépl., 1 plan dépl. en coul. in fine. Aix-en-Provence : Centre des Archives d'Outre-Mer, BIB SOM d4506; - s.l., 1978, 1. vol. (12, 274, 64, 19). Paris : Bibliothèque nationale de France, cote FOL- O3M- 1456. Dans l'exemplaire déposé aujourd'hui à la BnF, cette somme dactylographiée comprend un avertissement, une reproduction de l'article « Notice sur Gorée » écrit par le Dr Cariou (publiée dans La presqu'̂̀le du Cap-Vert. Dakar: IFAN, 1949, p. 273-282), le manuscrit Promenade à Gorée (274 p.), une bibliographie (64 p.) et des annexes (quatre partitions de chants goréens, 19 p.). La note d'avertissement nous indique que l'auteur a rédigé l'ouvrage sous la forme d'une conférence en 1951-1952, avec révision en 1977. Il n'aurait pas édité ce manuscrit sous le prétexte que sa "Notice sur Gorée » avait déjà été publiée au préalable dans La presqu'île du Cap-Vert (Dakar : IFAN, 1949), le Guide sur musée historique de l'AOF à Gorée (MAUNY, Raymond. Dakar : IFAN, 1955), et enfin Dakar et le Sénégal (Paris : Hachette, les Guides Bleus illustrés, 1972). Cariou est présent à Gorée au moment du bombardement de 1940 et aurait quitté l'île vers 1943. Durant son séjour, il amasse une documentation considérable sur l'île qu'il complète par la lecture des sources d'archives de la métropole. Le plan de Gorée qui accompagne le manuscrit porte la date de 1944. Il semblerait que ce soit cette " histoire » de la Maison des Esclaves écrite par Cariou qui ait servi de trame originelle au discours de l'ancien conservateur Joseph Ndiaye. En 1993, les auteurs du nouveau guide de l'île de Gorée sont plus nuancés et retiennent pour l'usage des petites pièces du rez-de-chaussée de la Maison des Esclaves une fonction mixte de "chambres " pour les « esclaves domestiques » et de «cellules » pour les esclaves de traite. (CAMARA, Abdoulaye, BENOIST, Joseph-Roger (de). Gorée. Guide de l'île et du Musée historique. Dakar : IFAN-Cheik Anta Diop, 1993, p. 12-13).

18. - Raymond Mauny débarque à Dakar le 13 décembre 1937 et y rencontre le professeur Théodore Monod, directeur de l'Institut Français d'Afrique Noire (IFAN), créé le 19 août 1936. Mauny est d'abord affecté dans les services du Gouvernement général. Durant la guerre, il 
prospecte notamment des sites préhistoriques autour de Dakar. En 1947, il est détaché de l'administration, puis intégré comme assistant à l'IFAN en 1949. Il s'occupe notamment de la protection des sites et des monuments historiques, et de ses prolongements en matière touristique, ainsi que de la mise en place des musées de Gorée, Dakar et Bamako. Pendant quinze ans (1947-1962), il dirige la section archéologie-préhistoire de l'IFAN. (BRASSEUR, Gérard. «Raymond Mauny ». 2000 ans d'histoire africaine. Le sol, la parole, l'écrit. Mélanges en hommage à Raymond Mauny. Paris : L'Harmattan, 1981, t. 1, p. 1-3).

19. Malgré son apport considérable au développement des recherches en AOF, notament dans le domaine de l'archéologie, Mauny est resté profondément conservateur, voire nihiliste. Il a systématiquement nié les apports de l'Afrique aux progrès techniques de l'humanité (invention du fer par exemple), contesté les contacts anciens avec la toute proche Méditerrannée. Ses positions ambigues lui valurent, au lendemain de la seconde guerre mondiale, d'être accusé de collaboration avec l'ennemi, ce qui lui valut une comparution devant la Chambre Civique du Parquet Général de l'AOF en son Audience du 4 décembre 1945. Il sera heureusement acquitté.

20. - MAUNY, Raymond. Guide de Gorée. Dakar: IFAN, Initiations Africaines: VII, 1951, p. 28 : "Quoi qu'en aient dit certains auteurs, il est bien peu probable que les négriers aient utilisé cette porte donnant sur la mer pour faire disparaître les cadavres. Le commerce des esclaves au $\mathrm{XVIII}^{\mathrm{e}}$ siècle se faisait au grand jour ; les négriers n'avaient nul besoin de " faire disparaître » des cadavres comme de vulgaires criminels, alors qu'ils jouissaient de la considération due à d'honnêtes commerçants. Et par ailleurs, drôle de façon de procéder, si l'on voulait passer inaperçu, que de jeter un cadavre à la mer à quelques mètres de sa maison... et à portée de ses narines, au surcroît ! Les esclaves étaient embarqués par chaloupes dans l'Anse, au grand jour, et s'il en mourait, ils étaient enterrés dans les lieux de sépulture que l'on retrouve partout dans l'île». Cette affirmation toute cartésienne doit être relativisée par le récit d'un témoin contemporain qui connaît bien les sites de traite de Gorée et de Saint-Louis, le chevalier de Boufflers. « Dans ce temps çi l'air du Sénégal est le pire de tous. Imagine que nous sentons de nos chambres, et surtout de la mienne, les exhalaisons des cadavres des captifs qui meurent par douzaines dans les cachots, et que les marchands, par économie, font jeter à l'eau pendant la nuit avec des boulets aux pieds. Les boulets se détachent à la longue, et les corps flottent entre deux eaux et vont s'arrêter sur le rivage, dans des endroits où l'on ne peut souvent pas arriver à pied ni en bateau. Ils restent entre les mangliers [= palétuviers et non "mangiers", selon Cyr Descamps] et ils y pourrissent à leur aise. Nous faisons des règlements pour parer à cela ; mais l'infection qui règne actuellement nous montre qu'ils ne sont pas suivis. » (Lettre datée du 9 juin 1786). PRAT, Paul. Lettres du chevalier de Boufflers à la comtesse de Sabran. Paris: Plon, 1891, p. 148-149.

21. - CAMARA, Abdoulaye, BENOIST, Joseph-Roger (de). Histoire de Gorée. Paris : Maisonneuve et Larose, 2003, p. 100-102. A.N. Sénégal, 4P 1442, Institut Français d'Afrique Noire (IFAN) à Dakar, aménagement, construction du musée de Gorée. Pièces écrites et plans, 1949-1953.

22. - MAUNY, Raymond. Guide du Musée historique de l'A.O.F. à Gorée. Dakar : IFAN, catalogue, nXIII, 1955, p. 11-21. Dans la salle consacrée à l'esclavage et son abolition, sont exposées une maquette du brick négrier nantais La Joséphine (1824), établie d'après les plans du Musée de la Marine à Paris, et des reproductions de documents relatifs à la traite et au transport des esclaves.

23. - Le Musée de la Mer correspond au savoir développé autour du laboratoire de biologie marine par l'IFAN. Il vient compléter ce dispositif touristique muséal et apporter une note exotique de villégiature balnéaire, en contrepoint du tourisme mémoriel. On y organise des expositions reflétant les interactions multiples entre les cultures ouest-africaines et les écosystèmes marins tout en faisant découvrir les instruments modernes d'océanographie.

24. - Décret du 25 janvier 1937 portant protection des monuments naturels et des sites de caractère historique, légendaire ou pittoresque, des colonies, pays de protectorat et territoires 
sous mandat relevant du ministère des Colonies. Arrêté n²805 du 16 octobre 1937 pour l'AOF (Journal officiel de l'AOF, p. 1063).

25. - Lettre d'André Villard au gouverneur général de l'AOF datée du 21 octobre 1937. Archives IFAN, C2/1.

26. - DELCOURT, Jean. Gorée, six siècles d'histoire. Dakar : Clairafrique, 1984, p. 96. À proximité de Dakar, Gorée est considérée comme une villégiature balnéaire et la Marine y installe une maison de repos.

27. - Arrêté du 15 novembre 1944 portant l'inscription sur la liste des monuments naturels et des sites de l'île de Gorée tout entière. Journal officiel de l'AOF, 9 décembre 1944, p. 834. Arrêté complémentaire du 15 février 1951 déclarant Gorée «site historique » et prévoyant une commission spéciale pour examiner les demandes d'autorisation de travaux. Journal officiel de l'AOF, 15 février 1951, p. 234, art. 36/1 à 36/3.

28. - Plan publié par Robert Gaffiot. La légende indique que l'état des habitations fut levé par le sergent Castel en 1932. Il représente les espaces où les maisons sont encore en état, les maisons en ruines et enfin l'emplacement des maisons ayant disparu. (GAFFIOT, Robert. Gorée, toute petite île. Doubs : Arcs-et-Senans, 1933, plan hors-texte).

29. - Lettre de Théodore Monod adressée au Gouverneur général de Dakar et dépendances datée du 8 juillet 1942. Archives IFAN, ${ }^{\circ}{ }^{812}$. (CAMARA, Abdoulaye, BENOIST, Joseph-Roger de. Histoire de Gorée, 2003, p. 135).

30. - MAUNY, Raymond. «En marge du centenaire de l'abolition de l'esclavage, l'île de Gorée ». Paris-Dakar, $\mathrm{n}^{\circ}$ 3732, 22 avril 1948, p. 29.

31. - Ancienne esclaverie construite au XVIII ${ }^{\mathrm{e}}$ siècle, (CAMARA, Abdoulaye, BENOIST, JosephRoger de. Histoire de Gorée, 2003, p. 110).

32. - Voir le site: http://fr.wikipedia.org/wiki/Boubacar_Joseph_Ndiaye [consulté le 25/04/2011].

33. - Voir le site : http://www.afrik.com/article9804.html [consulté le 17/06/2011].

34. - Le Soleil, 7 et 8 octobre 1978.

35. - Reportage documentaire sur l'île de Gorée, TF1, émission réalisée en mai 2005.

36. - Reportage documentaire sur l'île de Gorée, TF1, émission réalisée en mai 2005.

37. - Ndiaye, Boubacar Joseph. La maison des esclaves de Gorée. L'esclavage, ses origines et ses répercussions en Afrique; Gorée historique et traite des noirs à Gorée. Dakar: Maison des Esclaves de Gorée, 1986.

38. - «J'ai été tellement ému par ce que j'ai vu et entendu que j'en ai pleuré, car je viens de comprendre combien la traite négrière était inhumaine, combien mes ancêtres ont souffert depuis leur mise en captivité, leur séjour dans les esclaveries du littoral africain et dans les bateaux qui les ont transportés en Amérique. J'ai eu l'impression d'avoir remonté le temps et vécu moi-même leur calvaire ». Extrait du livre d'or du musée, d'après DIOP, Boubacar Boris, TOBNER, Odile, VERSCHAVE, François-Xavier. Négrophobie. Paris : Les Arènes, 2005).

39. - KI-ZERBO, Joseph. Histoire d'Afrique Noire, d'hier à demain. Paris: Hatier, 1972. ANGRAND, Jean-Luc. L'ouverture de la vraie captiverie de Gorée en 2010 - dixit «Indignez vous ». 13 avril 2010, en ligne http://jeanlucangrand.blogspot.com/2010/04/louverture-de-la-vraie-captiverie-de.html [consulté le 15/04/2011].

40. - DE ROUX, Emmanuel. «Le mythe de la Maison des esclaves qui résiste à la réalité ». Le Monde, 27 décembre 1996.

41. - DE ROUX, Emmanuel. «Le mythe de la Maison des esclaves qui résiste à la réalité ». Le Monde, 27 décembre 1996.

42. - SAMB, Djibril (dir). Gorée et l'esclavage, Actes du Séminaire sur "Gorée dans la traite atlantique: mythes et réalités ", Gorée, 7-8 avril 1997. Dakar: IFAN-CAD, Initiations et Études Africaines, 38, juillet 1997. Voir aussi : SMITH, Stephen. Nécrologie, Pourquoi l'Afrique meurt. Paris : Hachette-Plurielles, 
2004. DUARTE, Florence. Esclavage: la thèse qui choque Dakar: http://www.senegalaisement.com/ senegal/esclavage_senegal.php [consulté le 01/06/2011].

43. - ANGRAND, Jean-Luc. Céleste ou le temps des signares. Paris : Éditions Anne Pépin, 2006, p. 48. Voir la critique de l'ouvrage par Xavier Ricou qui souligne à juste titre l'absence de sources, des informations lacunaires, des erreurs. http://www.senegalmetis.com/Senegalmetis/Celeste.html [consulté le 20/06/2011].

44. - THIOUB, Ibrahima, BOCoUM, Hamady. "Gorée et les mémoires de la Traite atlantique ». Dans SAMB, Djibril (dir.). Gorée et l'esclavage, Actes du Séminaire sur Gorée dans la traite atlantique: mythes et réalités, Gorée, 7-8 avril 1997. Dakar: IFAN-CAD, Initiations et Études Africaines, 38, juillet 1997, p. 200.

45. - SECK, Ibrahima. «Esclavage et traite des esclaves dans les manuels de l'enseignement secondaire du Sénégal: des programmes de domestication coloniale aux programmes dits d'enracinement et d'ouverture ». Revue Historiens-Géographes du Sénégal, n8. Dakar: Faculté des Sciences et Technologies de l'Éducation et de la Formation, UCAD, 2009, p. 75. Bénin, Ouidah, Porte du non retour, http://fr.wikipedia.org/wiki/Fichier:Ouidah_Porte_du_Non_retour.jpg [consulté le 17/06/2011].

46. - NDIAYE, Boubacar Joseph Il fut un jour à Gorée... l'esclavage raconté à nos enfants. Paris : Lafon, 2006.

47. - THIAW, Ibrahima. «L'archéologie de l'île de Gorée au Sénégal. Chaque maison a une histoire ». Dans SANSONE, Livio, SOUMONNI, Élisée, BARRY, Boubacar (dir.). La construction transatlantique d'identités noires. Entre Afrique et Amériques. Paris: Karthala, 2010, p. 41-56 [trad. française de l'ouvrage paru en anglais en 2008, issu du colloque tenu à Gorée en 2002] ; THIAW, Ibrahima. "L'espace entre les mots et les choses : mémoire historique et culture matérielle à Gorée (Sénégal)». THIAW, Ibrahima (dir.). Espaces, culture matérielle et identités en Sénégambie. Dakar : CODESRIA, 2010, p. 18-40.

48. - La non implication dans le discours mémoriel ne signifie pas cependant désintérêt pour la préservation de l'île. De nombreux édifices ont été réhabilités et un important programme de protection de Gorée contre l'érosion marine sera élaboré et une recherche de financement entreprise. De même la requalification du Palais Roume en Auberge du Penseur a également été proposée par le Président Wade, sans connaître un début d'exécution.

49. - Poète, écrivain, homme politique, Léopold Sédar Senghor reprend la notion sur la Négritude, introduite par Aimé Césaire dès 1935, en la définissant ainsi : "La Négritude est la simple reconnaissance du fait d'être noir, et l'acceptation de ce fait, de notre destin de Noir, de notre histoire et de notre culture ». Fervent défenseur de la culture, la Négritude est pour lui «l'ensemble des valeurs culturelles de l'Afrique noire». VAILLANT, Janet G. Vie de Léopold Sédar Senghor. Noir, Français et Africain. Paris : Karthala, 2006. DIAGNE, Bachir «In Praise of the Postracial. Negritude beyond Negritude ». Third Text, Vol. 24, Issue 2, March, 2010, p. 241-248.

50. - Voir le site: http://www.assemblee-nationale.fr/histoire/senghor/senghobiographie.asp [consulté le 02/07/2011].

51. - Voir le site: http://www.au-senegal.com/Festival-mondial-des-arts-negres,2982.html [consulté le 06/06/2011] ; Second Congrès des artistes et écrivains noirs. Paris : Présence Africaine, $\mathrm{n}^{\circ} 27-28$, t. 1, février-mai 1959, p. 417.

52. - Léopold Sédar Senghor, 19 mars 1966, allocution radiodiffusée.

53. - Le premier Festival Mondial des Arts Nègres. Bruxelles : Marci, 1966. Le président du Festival Alioune Diop préside également l'Association du Festival Mondial des Arts Nègres. Trente-sept pays participent à ce premier festival, dont trente pays africains. Grâce au soutien financier du gouvernement du Sénégal et de la Société Africaine de Culture, ce festival s'organise autour de plusieurs manifestations : - un colloque sur « Fonction et signification sur l'Art Nègre dans la vie du peuple et pour le peuple (30 mars-8 avril)» (Condé-sur-Noireau : Présence Africaine, 1967) ; - 
un spectacle tous les soirs par des artistes, danseurs, musiciens de chaque pays participant au Festival ; - une exposition « L'Art Nègre, Sources Évolution Expansion » (Dakar-Paris, 1966.).

54. - Voir le site: http://www.ina.fr/art-et-culture/musique/video/CAF89027584/festival-desarts-negres-a-dakar.fr.html [consulté le 06/06/2011].

55. - À la demande des Sénégalais, le ministère français de la Coopération met à leur disposition Jean Mazel, qui a déjà réalisé en 1958 le spectacle de Marrakech. Le scénario est monté à partir des recherches menées par le département de l'IFAN sur l'histoire de Gorée. Ce scénario devait servir de canevas à un texte d'Aimé Césaire qui fut remplacé par Jean Brière, un Haïtien installé au Sénégal depuis 1964. Archives Nationales du Sénégal, FMAN 33 : Commission des spectacles. Spectacle féerique de Gorée. Opéra populaire en huit tableaux créé à l'occasion du premier Festival mondial des arts nègres. 1-24 avril 1966, Dakar. D'après Cyr Descamps, le spectable aurait été conçu en collaboration avec Charles Carrère.

56. - Dans les premières séquences du film Little Senegal de Richard Bouchareb, les touristes noirs américains sont saisis par l'émotion lors de la visite de la Maison des Esclaves. BOUCHAREB, Richard. Little Senegal, Tadrart Film, 2000, 1h38, long métrage algérien, français, allemand.

57. - Extrait de l'« Appel du Directeur général pour la sauvegarde de Gorée, 22 décembre 1980 ». Les Nouvelles de l'Unesco, n41, 5 janvier 1981, p. 1-3. L'engouement des Américains pour la généalogie remonte à 1976, avec la parution de l'ouvrage de HALEY, Max. Roots. The Saga of an American Family, repris dans les séries télévisées Roots de 1977 et 1979. L'île de Gorée y est présentée comme "gataway to Roots". Sur la marchandisation touristique de l'île de Gorée: EBRON, Paulla A. "Tourists as pilgrims: Commercial fashioning of transatlantic politics ". American Ethnologist, nov. 1999, 26, 4, p. 910-932. http://www.nyu.edu/classes/bkg/tourist/ebronafrica.pdf [consulté le 26/02/2013]

58. - Voir le site : http://www.goreediasporafestival.org/accueil.html [consulté le 06/06/2011].

59. - Île de Gorée. Zone urbaine de Dakar. Paris : Eurétudes, 1968. Le programme d'aménagement insiste sur cinq recommandations essentielles : la restauration et l'amélioration de l'urbanisme général du site par la création d'un complexe hôtelier moderne sur le Castel, le développement du centre de pêche sportive par une extension de la capacité d'accueil des installations au niveau du Relais de l'Espadon, la réalisation d'un équipement portuaire favorisant l'amélioration de la liaison maritime avec la ville de Dakar et enfin l'édification de nouvelles maisons d'un type particulier.

60. - Voir le site : http://archiwebture.citechaillot.fr/awt/asso/FRAPN02_AADOC_REPERAGE.pdf [consulté le 21/06/2011].

61. - Voir le site: http://www.senegalmetis.com/Senegalmetis/30_ans_de_classement.html [consulté le 21/06/2011].

62. - DESCAMPS, Cyr. Préservation et mise en valeur du patrimoine national (décembre 1969 - janvier 1970). Paris : UNESCO, 1970.

63. - Convention et recommandations de l'UNESCO relatives à la protection du patrimoine culturel. Paris : UNESCO, 1983.

64. - Le critère VI de 1972 est d'« être directement ou matériellement associé à des événements ou des traditions vivantes, des idées, des croyances ou des œuvres artistiques et littéraires ayant une signification universelle exceptionnelle ». En 1977, le critère d'inscription de l'île de Gorée mentionne qu'elle: «... occupe une place de choix dans le patrimoine sénégalais en tant que vestige de choc de deux civilisations différentes, et le témoin d'une expérience humaine sans précédent dans l'histoire des peuples. En effet, Gorée est pour la conscience universelle, le symbole de la traite négrière avec son cortège de souffrance, de larme et de mort. L'attention que les autorités sénégalaises portent à cette île ne se réfère pas à un désir de s'attarder sur le passé à jamais enfoui, mais à une volonté de faire de l'île de Gorée l'archétype de la souffrance de l'homme noir à travers les âges à l'instar de tant d'autres lieux tristement célèbres où l'aveuglement et la haine ont naguère sévi. De plus, par-delà cet aspect historique, l'île de Gorée 
constitue en elle-même un ensemble architectural digne d'intérêt dont la conservation tel quel, est une des priorités du programme sénégalais de protection du patrimoine [...]» (Formulaire de proposition d'inscription $n^{\circ}$ CC-77/WS/64. Dans GONODOU, Alain, ASSOMO, Lazare Éloundou. État de conservation de l'île de Gorée, rapport de mission ICOMOS (28 mars - 3 avril 2004). Centre du patrimoine mondial - ICOMOS, 2004, p.7, en ligne: http://whc.unesco.org/archive/2004/ mis-26-2004.pdf [consulté le 25/04/2011]).

65. - GRÉGOIRE, A. Sénégal. Monuments historiques de l'île de Gorée et de Saint-Louis du Sénégal. Paris : UNESCO, mai 1974, mss. dactyl. http://unesdoc.unesco.org/images/0001/000102/010200FB.pdf [consulté le 25/07/2011].

66. - FRAPOLLI, Jean-Pierre, CLERC, Maurice. Plan directeur de rénovation de l'île de Gorée. Aspects juridiques et financiers du programme de rénovation de l'île. Paris: UNESCO, 1975. http:// unesdoc.unesco.org/images/0001/000161/016127fb.pdf [consulté le 25/07/2011].

67. - PARENT, Michel. L'avenir de Gorée. Paris : UNESCO, 1977, FMR/ CCT/ CH/ 77/ 184.

68. - LABLAUDE, Pierre-André. Réhabilitation du site historique de l'île de Gorée. Projet touristique de la Petite Côte. Sénégal. Paris : UNESCO, 1978. FMR/CC/CH/78/260(BIRD) ; 9988.SEN/21.

69. - UNESCO. Plan d'action pour la sauvegarde du patrimoine architectural de lîle de Gorée. 1981. http://unesdoc.unesco.org/images/0004/000459/045955fb.pdf [consulté le 26/04/2011].

70. - Il s'agit de Michel Van der Meerschen (depuis le classement de l'île en 1978, jusqu'en 1982), puis de Françoise Descamps et Dirk Defraeije (en poste à partir de 1982).

71. - UNESCO . Gorée, island of memories. Paris: Unesco, 1985 (en anglais): http:// www.worditude.com/ebooks/unescopdf/goree.pdf [consulté le 06/04/2011]. L'UNESCO a aussi contribué à l'émission de timbres, [voir ad. Internet]. Au cours des années 2000, l'UNESCO a conçu un site internet pour une visite virtuelle de Gorée: http://webworld.unesco.org/goree/fr/ index.shtml [consulté 07/04/2011].

72. - Gorée, île mémoire: Campagne internationale de sauvegarde. 1985, réd. 2008. http:// unesdoc.unesco.org/images/0018/001803/180301m.pdf [consulté le 26/07/2011].

73. - « Appel du Directeur général pour la sauvegarde de Gorée, 22 décembre 1980 ». Les Nouvelles de l'UNESCO, n41, 5 janvier 1981, p. 1-3.

74. - Gorée, Guide de l'île et du musée historique. Dakar : IFAN, Musée Historique, 1993.

75. - LABLAUDE, Pierre-André. Préservation et restauration de l'île de Gorée. Paris : UNESCO, 1982. http://unesdoc.unesco.org/images/0005/000511/051197fo.pdf [consulté le 25/07/2011].

76. - GODONOU, Alain, ASSOMO, Lazare Éloundou. État de conservation de l'île de Gorée, rapport de mission ICOMOS (28 mars - 3 avril 2004). Centre du patrimoine mondial - ICOMOS, 2004, p. 7. http://whc.unesco.org/archive/2004/mis-26-2004.pdf [consulté le 25/04/2011].

77. - Ce sont des «travaux de réparation consécutifs à l'effondrement d'un mur porteur au rezde-chaussée "... " Les restaurations effectuées concernent certains éléments décoratifs supposés avoir disparu». (CAMARA, Abdoulaye, BENOIST, Joseph-Roger (de). Histoire de Gorée. Paris: Maisonneuve et Larose, 2003, p. 110).

78. - En 1990-1991, une nouvelle campagne de restauration de la Maison des esclaves a été entreprise avec l'aide financière du Comité France-Liberté. Les travaux devaient permettre de reconstituer à l'étage « une pièce d'habitation d'époque, décorée de meubles et d'objets pour la plupart d'origine ", et de présenter une exposition de documents sur la vie quotidienne à Gorée au XVIII ${ }^{\mathrm{e}}$ siècle.

79. - Adolphe d'Hastrel de Rivedoux, peintre, aquarelliste, lithographe, embrasse la carrière militaire et devient capitaine d'artillerie dans la marine. Au cours de ses périples, il fait escale au Sénégal en 1836 et y séjourne à nouveau en 1839. Lors de ce dernier passage, il réalise notamment une série d'aquarelles d'une grande précision sur Gorée, qu'il reproduira lui-même dans un album lithographique qu'il publie près de dix ans plus tard sous le titre «Colonie française du Sénégal ». Deux aquarelles nous donnent un état de la Maison dite des esclaves en 1839. Une vue de la cour intérieure de la Maison dite d'Anna Colas (ou Annacolas Pépin), portant la date du 20 
février 1839. La vue a été inversée lors de la reprise lithographique effectuée par d'Hastrel luimême. Une première épreuve de travail porte la mention en bas à gauche : À Gorée 20 février 1839 et à droite, après la signature [illisible]. Cette lithographie porte ensuite le titre: Une habitation à Gorée (Maison d'Anna Colas) pour être insérée comme la planche $n^{\circ} 8$ de l'album imprimé par Auguste Bry à Paris sur la « Colonie française du Sénégal », s.d. [vers 1848]. La façade sur l'actuelle rue Saint-Germain figure sur un second dessin aquarellé, daté du jour suivant, le 21 février 1839. La lithographie de l'aquarelle est signée par Théodore du Moncel et figure dans l'album sous le $n^{\circ} 3$. Le revers de l'aquarelle porte une esquisse de la rue Saint-Germain, vue du côté opposé. MAUNY, Raymond. "Aquarelles et dessins de d'Hastrel relatifs au Sénégal (1839)». Dans Notes africaines, n52, octobre 1951, p. 113-116 ; RICOU, Xavier. Trésors de l'iconographie du Sénégal colonial. Marseille: Riveneuve, 2007, p. 112-113. http://fr.wikipedia.org/wiki/ Adolphe_d\%27Hastrel [consulté le 02/08/2011]. http://www.senegalmetis.com/Senegalmetis/ Signare_E4-6_dHastrel6.html [consulté le 02/08/2011]. Aquarelle achetée en 1951 par l'IFAN et qui aurait disparu. http://www.senegalmetis.com/Senegalmetis/Signare_E7_dHastrel3.html [consulté le 02/08/2011]. Aquarelle, collection Marie-José Crespin.

80. - UNESCO. Rapport Lablaude, Préservation et restauration de l'île de Gorée. 1982, p. 14.

81. - Voir le site : http://www.geolocation.ws/v/I/5556385582830076641-5560936314785677810/ maison-des-esclaves---la-porte-sans/en [consulté le 02/08/2011]. État décembre 2010 : terrasse en cours de construction.

82. - RICOU, Xavier. « Gorée, ville métisse ». Dans CAMARA, Abdoulaye et BENOIST, Joseph Roger de. Histoire de Gorée. Paris : Maisonneuve et Larose, 2003, p. 92.

83. - Les trois établissements sont: la Maison du Soudan, devenue un centre d'étude; la Capitainerie du port, servant provisoirement d'annexe à l'Université des Mutants; la Maison Victoria Albis, accueillant des expositions, ainsi que les locaux du Bureau d'architecture des monuments historiques et la résidence de l'expert de l'UNESCO envoyé à Gorée. HAARDT, Caroline. « Gorée, l'île aux esclaves ». Courrier de l'UNESCO, octobre 1992, p. 48-50.

84. - UNESCO, 27ème session du Comité du Patrimoine mondial : État de conservation des biens inscrits sur la liste du patrimoine en péril, référence WHC-03/27.COM/7B, 2003, p. 27, en ligne http:// whc.unesco.org/archive/2003/whc03-27com-07bf.pdf [consulté le 06/04/2011].

85. - Voir le site: http://www.abolitions.org/index.php?IdPage=1173454388 [consulté le 16/07/2011].

86. - MATSUURA, Koichiro. «Discours prononcé lors du lancement de l'année internationale de la commémoration de la lutte de l'esclavage et de son abolition à Cape Coast (Ghana) en 2004 ». Bulletin d'information de l'Unesco, numéro spécial, 2004.

87. - GUEYE, Mbaye. Sites liés à la traite négrière et à l'esclavage en Sénégambie. Pour un tourisme de mémoire. UNESCO, 2005 [secteur de Gorée, p. 35-48]. http://unesdoc.unesco.org/images/ 0014/001401/140126f.pdf.

88. - Le Musée maritime de Merseyside à Liverpool, point de départ du trafic de la traite anglaise abrite depuis 1994 une Transatlantique Slavery Gallery, qui est devenue en 2007 un musée international permanent consacré à la traite transatlantique. http:// www.liverpoolmuseums.org.uk/ism/.

89. - « Gorée, La Maison des Esclaves, Sénégal ». Dakar : Foreign and Commonwealth Office/ National Museum galleries on Merseyside/The britisch Council, s. d. [2001 ?], [Brochure exposition].

90. - Voir les trois vidéos de l'exposition de Lamine Barro sur You Tube: http:// www.youtube.com/watch?v=bNnQPMDjgMs ; $\quad$ http://www.youtube.com/watch? $\mathrm{v}=\mathrm{fK} 09 \mathrm{VV}$ pum2c\&feature=related ; $\quad \mathrm{http} / /$ www.youtube.com/watch? $\mathrm{v}=$ HXo5Lijegrg\&feature=related. L'exposition a été également présentée au Musée de l'IFAN à Dakar et dans d'autres lieux : http://www.comite-memoire-esclavage.fr/spip.php?article423. 
91. - Le Soleil, 26 novembre 1976. Cette idée du président Senghor a été reprise une génération plus tard par le président Wade pour la construction de sa statue géante de La Renaissance africaine.

92. - Le Soleil, 26 novembre 1976.

93. - En 1998-1999, ce concours international a également inspiré de nombreux mémoires de Travaux personnels de fin d'études (TPFE) pour l'obtention du diplôme d'architecte DPLG dans les écoles d'architecture de Paris-la-Seine, Paris-Villemin, Grenoble, Nantes, Marne-la-Vallée, Lyon... http://portail.documentation.developpement-durable.gouv.fr/ArchiResWiki/index.php/ ACC\%C3\%88S\%C3\%80_LA_BASE : Gorée [consulté le 21/07/2011].

94. - Voir les sites: http://www.unesco.org/bpi/fre/unescopresse/97-150f.htm [consulté le 21/07/2011]. http://www.odb.it/goree.htm [consulté le 01/08/2011]. http:// europaconcorsi.com/projects/159587-Gor-e-Memorial/slideshow [consulté le 01/08/2011].

95. - Voir le site: http://www.uia-architectes.org/texte/nouvelles/1a1z1a.html [consulté le 21/07/11].

96. - Le Soleil, 14 janvier 1998. Allocution du président de la République du Sénégal lors de la remise des prix aux lauréats du Mémorial de Gorée.

97. - Voir le site: http://www.unesco.org/bpi/fre/unescopresse/98-07f.htm [consulté le 21/07/2011].

98. - WHC-10/34.COM/8E.Add.2. Brasilia, $1^{\text {er }}$ août 2010, http://whc.unesco.org/archive/2010/ whc10-34com-8E.Add2f.pdf [consulté le 21/07/2011].

99. - Voir le site : http://www.memorial-goree.com/ [consulté le 21/07/2011].

100. - Voir le site : http://www.gudev.cz/ [consulté le 21/07/2011].

101. - Le projet de 2011 réapparaît en novembre 2012, porté ( ?) par le ministre de la culture avec l'aide d'Amadou Lamine Sall. Le symbole du navire est repris, dessiné par le studio tchèque Helika. http://www.helika.cz/\#/projekty/aktualni/1619 [consulté le 27/02/2013].

102. - THIAM, Alassane, THILMANS, Guy. «Gorée l'île musée, Création d'un musée historique ». Museum, volume XXXII, $n^{\circ}$ 3, p. 119-129.

103. - Gorée, Guide de lîle et du musée historique. IFAN : Musée Historique, 1993. Pour l'histoire du musée historique : DESCAMPS, Cyr et CAMARA, Abdoulaye. «Le Musée Historique : cinquante ans de présence à Gorée (1954-2004) ». Senegalia. Études sur le patrimoine ouest-africain. Saint-Maur-desFossés, Sépia, 2006, p. 150-160.

104. - Voir le site : http://mufem.org/index.php [consulté le 21/08/2011].

105. - Pour l'histoire de ce musée: http://fr.wikipedia.org/wiki/ Mus\%C3\%A9e_de_la_Femme_Henriette-Bathily [consulté le 13/10/2011].

106. - En avril 2011, ce Musée de la Femme était fermé depuis quelques mois.t. Deux ans plus tard, la décision de délocaliser ce musée sur le continent est effective . Les expositions sont en cours de démontage.

107. - MONOD, Théodore. «Le musée de la mer, Gorée, Sénégal ». Museum international, vol. 14, déc. 1961, p. 1-11.

108. - UNESCO-BREDA (Bureau Régional de Dakar). Répertoire des musées du Sénégal. Dakar : Grafiti, 2008, en ligne: http://wamponline.org/Repertoire_des_musees_du_senegal.pdf [consulté le 21/06/2011].

109. - Parmi les partenaires il faut citer l'Association des amis du musée, et le projet Chélonée. 110. - TOULIER, Bernard. «Architecture coloniale, identités culturelles et patrimoine en Afrique francophone ». Dans ANDRIEUX, Jean-Yves (dir.). Patrimoine, sources et paradoxes de l'identité. Rennes : Presses universitaires de Rennes, 2011, p. 117-142.

111. - LABLAUDE, Pierre-André. «À Gorée au Sénégal : l'île aux esclaves ». Monuments Historiques, n¹62, fév.-mars 1989, p. 88-92. L'auteur prône une "pratique [patrimoniale] métissée, parfois lointaine des préceptes rigides d'une Charte de Venise vieillie et perçue de plus en plus comme 
attardée dans une guerre de tranchée post-viollet-le-ducienne, à la dialectique trop exclusivement européenne ».

112. - BOCOUM, Hamady. "Gorée et les mémoires de la Traite atlantique ». Dans SAMB, Djibril (dir.). « Gorée et l'esclavage », Actes du Séminaire sur « Gorée dans la traite atlantique : mythes et réalités ». Gorée, 7-8 avril 1997. Dakar : IFAN-CAD, Initiations et Études Africaines, 38, juillet 1997, p. 200.

113. - FRANK, Robert. « La mémoire et l'histoire ». Dans VOLDMAN, Danièle (dir.). La Bouche de la vérité ? «La recherche historique et les sources orales ». Les cahiers de l'Institut d'histoire du temps présent, n²1, nov. 1992, p. 65-72.

\section{RÉSUMÉS}

L'île de Gorée est aujourd'hui un des symboles emblématiques de la mémoire de la traite atlantique. Dès la période coloniale, une «maison des esclaves » est proposée pour l'accueil des touristes et le "centre historique » de l'île protégé au titre des monuments historiques et des sites avec l'ouverture d'un musée historique de l'Afrique occidentale française. À partir de l'indépendance, l'État du Sénégal prend le relais. Le discours patrimonial national rejoint la demande de connaissance sur les « racines » de la diaspora noire des afro-descendants : le site est mis sur la liste du patrimoine mondial en 1978, un projet de mémorial est lancé sous l'égide de l'UNESCO et une campagne internationale de sauvegarde est initiée par l'organisation internationale. Mais seule une réplique, dont l'impact négatif est évident, a été édifiée sur l'île. Aujourd'hui, on assiste à une surenchère de cette construction de la mémoire et du patrimoine à travers le projet d'édification d'un nouveau "mémorial de Gorée » sur le site des Amaldies à Dakar. Au-delà du discours du célèbre conservateur du musée de la Maison des esclaves, Boubacar Joseph Ndiaye, aujourd'hui décédé, ne faut-il pas reconvertir l'ensemble des musées de l'île pour accompagner cette transmission de la mémoire et cette demande d'« histoire »?

\section{INDEX}

Mots-clés : patrimoine, Gorée, esclavage, Sénégal

\section{AUTEURS}

\section{HAMADY BOCOUM}

directeur du patrimoine culturel, ministère de la culture, Sénégal directeur de l'Institut fondamental d'Afrique noire, université Cheikh Anta Diop, Dakar hawab@hotmail.com

\section{BERNARD TOULIER}

conservateur général du patrimoine, direction générale des patrimoines, ministère le la Culture et de la Communicationbernard.toulier@culture.gouv.fr 